\title{
Efficacy and safety outcomes of sofosbuvir-based treatment regimens for hepatitis $C$ virus-infected patients with or without cirrhosis from phase III clinical trials
}

Young-Mo Yang
Eun Joo Choi

Eun Joo Choi

Department of Pharmacy, College of Pharmacy, Chosun University, Gwangju, South Korea
Correspondence: Eun Joo Choi Department of Pharmacy, College of Pharmacy, Chosun University, 309 Pilmun-daero, Dong-gu, Gwangju 61452, South Korea

Tel +82622306382

Fax +82 622225414

Email ejchoi@chosun.ac.kr

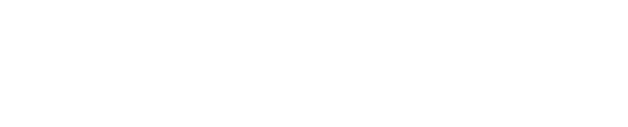

Background: With the appearance of oral direct-acting antivirals (DAAs), the field of hepatitis $\mathrm{C}$ virus (HCV) treatment has been dramatically changed. This evolution makes possible for all oral treatments to be available for the treatment of $\mathrm{HCV}$-infected patients. The aims of this review were to report the efficacy and safety of sofosbuvir (SOF)-based regimens for the treatment of patients with chronic HCV infection and to provide our clinical perspectives on these regimens.

Methods: A literature search of clinical studies published in PubMed and posted on ClinicalTrials.gov website was performed to identify studies evaluating the efficacy or safety of SOF-containing treatment regimens.

Results: A total of 23 clinical trials were examined in the review. The evaluated SOF-based regimens are as follows: $\mathrm{SOF} /$ daclatasvir $(\mathrm{DCV}) \pm$ ribavirin $(\mathrm{RBV}), \mathrm{SOF} /$ ledipasvir $(\mathrm{LDV}) \pm$ $\mathrm{RBV}, \mathrm{SOF} /$ simeprevir (SMV), SOF/velpatasvir (VEL) $\pm \mathrm{RBV}$, and SOF/RBV \pm peginterferon (peg-IFN). These SOF-based regimens were at least effective and safe for $\mathrm{HCV}$-infected patients with or without cirrhosis. The SOF/VEL $\pm \mathrm{RBV}$ regimen, a pan-genotypic DAA regimen, was effective for the treatment of patients with HCV genotype 1, 2, 3, 4, 5, or 6 infection. The 24-week SOF/RBV regimen was as effective as the 12-week SOF/RBV/peg-IFN regimen. Patients with HCV genotype 3 infection could have benefits from the use of the 24-week SOF/ RBV regimen. For cirrhotic patients with HCV genotype 3 infection, the 12-week SOF/RBV/ peg-IFN regimen could be considered as an alternative treatment option when access to SOFbased regimens with other DAAs is limited. In the included studies, significant adverse events due to SOF-based regimens were not reported.

Conclusion: The clinical trials suggest that SOF-based treatment regimens for HCV-infected patients with or without cirrhosis can be at least effective and safe patient-convenient medications. However, it is necessary to monitor HCV-infected patients, since rare adverse events, drug-drug interactions, and drug-disease interactions can occur in real clinical settings.

Keywords: hepatitis C, direct-acting antiviral, sofosbuvir, efficacy, safety, drug-drug interaction

\section{Introduction}

Chronic infection with hepatitis $\mathrm{C}$ virus (HCV) can result in the development of cirrhosis and hepatocellular carcinoma (HCC). The global prevalence of chronic hepatitis $\mathrm{C}(\mathrm{CHC})$ is $1.1 \%$, which corresponds to $\sim 80$ million people with detectable HCV RNA. ${ }^{1}$ The areas with the highest prevalence rates $(\geq 2.5 \%)$ include West Africa, 
Eastern Europe, and Central Asia. ${ }^{1}$ Generally, HCV-infected people reside in low- and middle-income countries. ${ }^{2}$

Recently, there has been a shift in the standard treatment for chronic $\mathrm{HCV}$ infection from injectable interferon (IFN) with ribavirin (RBV) to oral, direct-acting antivirals (DAAs). ${ }^{3}$ With the advent of DAAs, IFN-free therapeutic regimens for the treatment of chronic $\mathrm{HCV}$ infection are now allowed. These regimens lead to remarkable improvements in sustained virologic response (SVR12), defined as undetectable HCV RNA levels 12 weeks after the end of the treatment, thereby providing therapeutic options to patients with contraindications or low prior SVR to IFN-based regimens. ${ }^{4-6}$ In particular, regimens using sofosbuvir (SOF), a pan-genotypic HCV nucleotide polymerase inhibitor, provide more convenient dosing schedules by shortening the duration of treatment to $12-24$ weeks and lead to cure rates close to $90 \%$. $^{7-11}$

Oral IFN-free regimens, which consist of at least two DAAs, including SOF, have tolerable adverse effects (AEs). The common AEs from these regimens include fatigue, headache, insomnia, and diarrhea, which usually are not serious. ${ }^{9,10,12-14}$ Each DAA has its own metabolic pathway and exhibits different drug-drug interactions (DDIs); thus, management of DDIs and AEs is critical in clinical practice. Most DDIs are associated with cytochrome P450 3A4 (CYP3A4) or P-glycoprotein (P-gp) activities. ${ }^{15}$ The induction or inhibition of CYP3A4 or P-gp may cause abnormal DAA exposure, thereby negatively affecting efficacy and safety. The concurrent use of dual CYP3A4 and P-gp inducers, such as carbamazepine and rifampin, with SOF may result in reduced SOF exposure. The risk for bradycardia may also increase when DAAs are coadministered with amiodarone. ${ }^{16}$

The aims of this review were to report the efficacy and safety of SOF-based regimens for the treatment of patients with chronic HCV infection and to provide our clinical perspectives on these regimens.

\section{Methods}

A literature search was performed to identify clinical trials of $\mathrm{HCV}$-infected patients that evaluated the efficacy or safety of SOF-containing treatment regimens. PubMed was searched, using "sofosbuvir" as the search term, to find clinical trials published in English no later than November 2016. The reference lists of the selected articles and related reviews were used to identify additional articles. Data posted on the ClinicalTrials.gov website were also utilized to find clinical outcomes that were not yet published but had been posted on the website. Two reviewers independently scanned the article titles and abstracts and identified relevant studies that met the following criteria: 1) only prospective, phase III clinical studies; 2) only patients with HCV infection; 3) SOF must have been used for the treatment of the HCV infection; and 4) the end points had to contain the proportion of patients with an SVR.

\section{Results}

Through the literature search (Figure 1), 23 eligible clinical trials were identified that met the predefined inclusion criteria. The relevant findings from the selected trials are presented in Tables 1 and 2. ${ }^{8-14,17-32}$

\section{SOF in combination with daclatasvir}

SOF was used in combination with daclatasvir (DCV) in three clinical trials. A total of 50 patients with $\mathrm{HCV}$ genotype 3 and advanced liver disease were enrolled in the open-label, randomized clinical trial conducted by Leroy et $\mathrm{al}^{10}$ in Australia and France. The patients received DCV (60 mg, once daily), SOF (400 mg, once daily), and RBV (weight-based 1,000 or 1,200 mg/day in two divided doses) for 12 or 16 weeks. The proportion of patients with SVR12 (HCV RNA $<25 \mathrm{IU} / \mathrm{mL}$ ) was $87.5 \%$ and $92.3 \%$ in the groups treated for 12 and 16 weeks, respectively. Of 36 cirrhotic patients, $86.1 \%$ (12 weeks, $83.3 \%$; 16 weeks, $88.9 \%$ ) reached SVR12. Overall, 94.0\% of patients (12 weeks, 95.8\%; 16 weeks, 92.3\%) experienced at least one AE, but AEs did not lead to discontinuation of treatment.

In another open-label clinical study in the USA, 60 and $53 \mathrm{HCV}$ patients with advanced cirrhosis and postliver transplantation disease recurrence, respectively, were enrolled. ${ }^{13}$ The patients received DCV (60 mg, once daily), SOF (400 mg, once daily), and RBV (600 mg, once daily, up to $1,000 \mathrm{mg}$ based on hemoglobin and creatinine clearance) for 12 weeks. SVR12 (HCV RNA < 25 IU/mL) was achieved in $83.3 \%$ and $94.3 \%$ of the advanced cirrhosis cohort (ACC) and the post-transplantation cohort (PTC), respectively. No treatment-related serious AEs occurred, and there were no deaths during the treatment period. Two patients in the ACC (with anemia and noncardiac chest pain) and two in the PTC (with arthralgia and headache) experienced treatmentassociated grade 3 (severe) or 4 (life-threatening) AEs.

In the open-label, two-cohort clinical trial conducted by Nelson et $\mathrm{al}^{22}$ in the USA, 101 treatment-naive (TN) and 51 treatment-experienced (TE) patients with $\mathrm{HCV}$ genotype 3 infection were enrolled. DCV (60 mg, once daily) and SOF (400 mg, once daily) were coadministered to the patients for 12 weeks. Overall, SVR12 (HCV RNA $<25 \mathrm{IU} / \mathrm{mL}$ ) was 


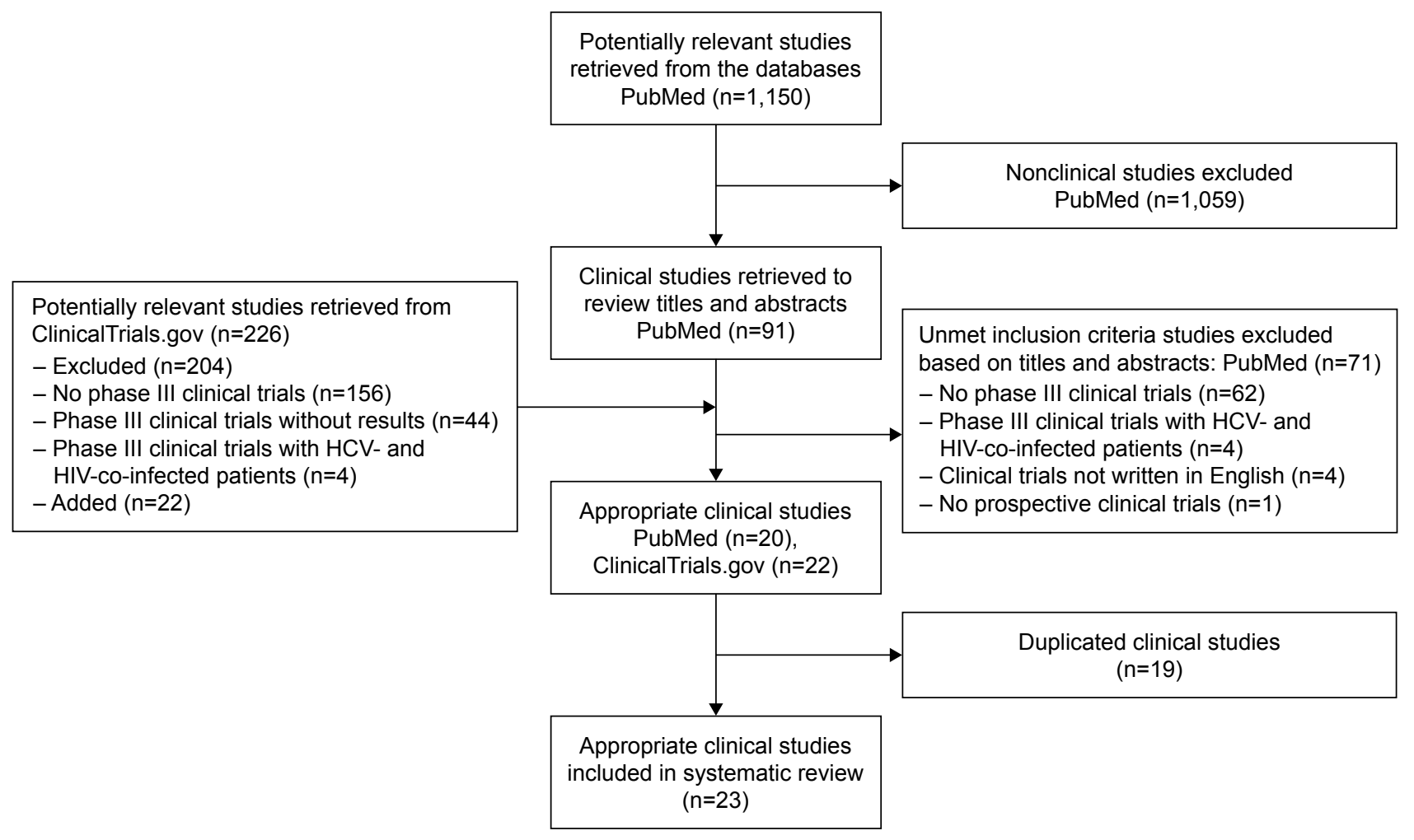

Figure I Flowchart of the study selection process.

Abbreviations: HCV, hepatitis C virus; HIV, human immunodeficiency virus.

attained in $90.1 \%$ and $86.3 \%$ of the $\mathrm{TN}$ and $\mathrm{TE}$ patients, respectively. Of the TN and TE cirrhotic patients, 11 (57.9\%) and nine $(69.2 \%)$ patients, respectively, reached SVR12. Only one serious AE (gastrointestinal hemorrhage) occurred with treatment, but it was considered unrelated to the study medications. There were no deaths during the treatment period. No grade 4 AEs were reported, and grade 3 AEs occurred in three patients (one arthralgia, one food poisoning and nausea/vomiting, and one serious AE of gastrointestinal hemorrhage).

\section{SOF in combination with ledipasvir}

Ledipasvir (LDV) plus SOF with and without RBV was used in four clinical trials. In the open-label, randomized clinical trial conducted by Mizokami et $\mathrm{al}^{21}$ in Japan, 171 and 170 patients with $\mathrm{HCV}$ genotype 1 infection were enrolled in the LDV/SOF and LDV/SOF/RBV groups, respectively. The patients received LDV (90 mg, once daily), SOF (400 mg, once daily), and RBV (weight-based 600, 800, or $1,000 \mathrm{mg} /$ day in two divided doses) for 12 weeks. The rates of SVR12 (HCV RNA <25 IU/mL) were $100.0 \%$ and $98.2 \%$ in the LDV/SOF and LDV/SOF/RBV groups, respectively. Among TN patients with cirrhosis, 13 (100.0\%) in the LDV/SOF group and $11(91.7 \%)$ in the LDV/SOF/RBV group reached SVR12. Among TE patients with cirrhosis, $28(100.0 \%)$ in the LDV/SOF group and $23(100.0 \%)$ in the LDV/SOF/RBV group reached SVR12. Overall, 240 (70.4\%) patients had at least one AE, and most experienced only mild (grade 1) AEs. The occurrence rates of AEs were higher in the LDV/SOF/RBV group (75.3\%) than in the LDV/ SOF group (65.5\%). One patient receiving LDV/SOF/RBV discontinued treatment due to an RBV-related morbilliform drug eruption. One patient receiving LDV/SOF/RBV died from cardiac arrest.

In another open-label, randomized clinical trial conducted by Afdhal et $\mathrm{al}^{23}$ in the USA, 440 patients with previously treated HCV genotype 1 infection were enrolled. All patients were randomly assigned to four treatment groups: LDV/ SOF for 12 weeks (109 patients), LDV/SOF for 24 weeks (109 patients), LDV/SOF/RBV for 12 weeks (111 patients), and LDV/SOF/RBV for 24 weeks (111 patients). Each patient received LDV (90 mg, once daily) and SOF (400 mg, once daily), with or without RBV (weight-based 1,000 or $1,200 \mathrm{mg} /$ day in two divided doses) during the treatment period. SVR12 (HCV RNA <25 IU/mL) was achieved in $93.6 \%$ and $99.1 \%$ of patients receiving LDV/SOF for 12 and 24 weeks, respectively. SVR12 was also achieved in $96.4 \%$ and $99.1 \%$ of those receiving $\mathrm{LDV} / \mathrm{SOF} / \mathrm{RBV}$ for 12 and 


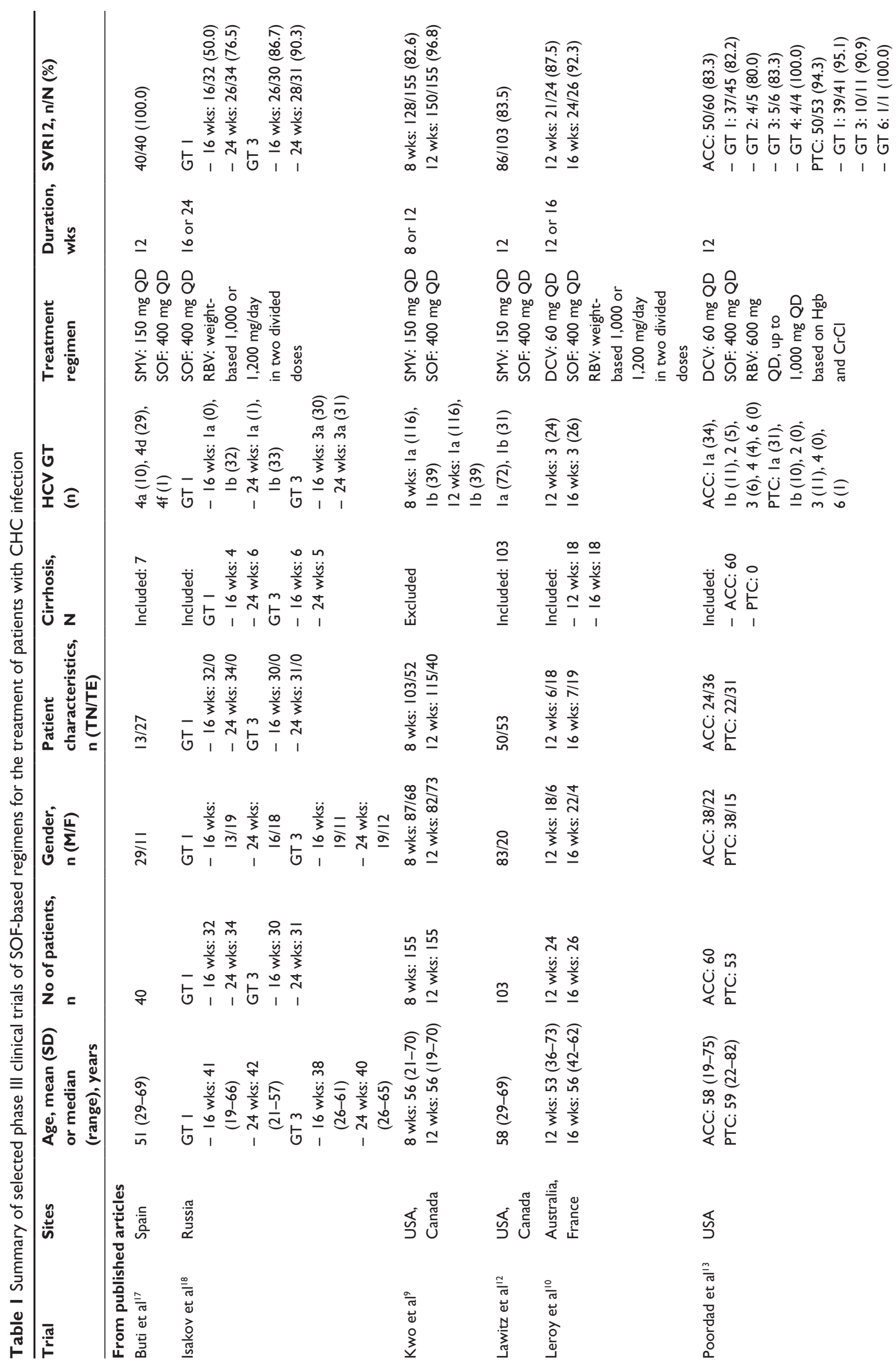




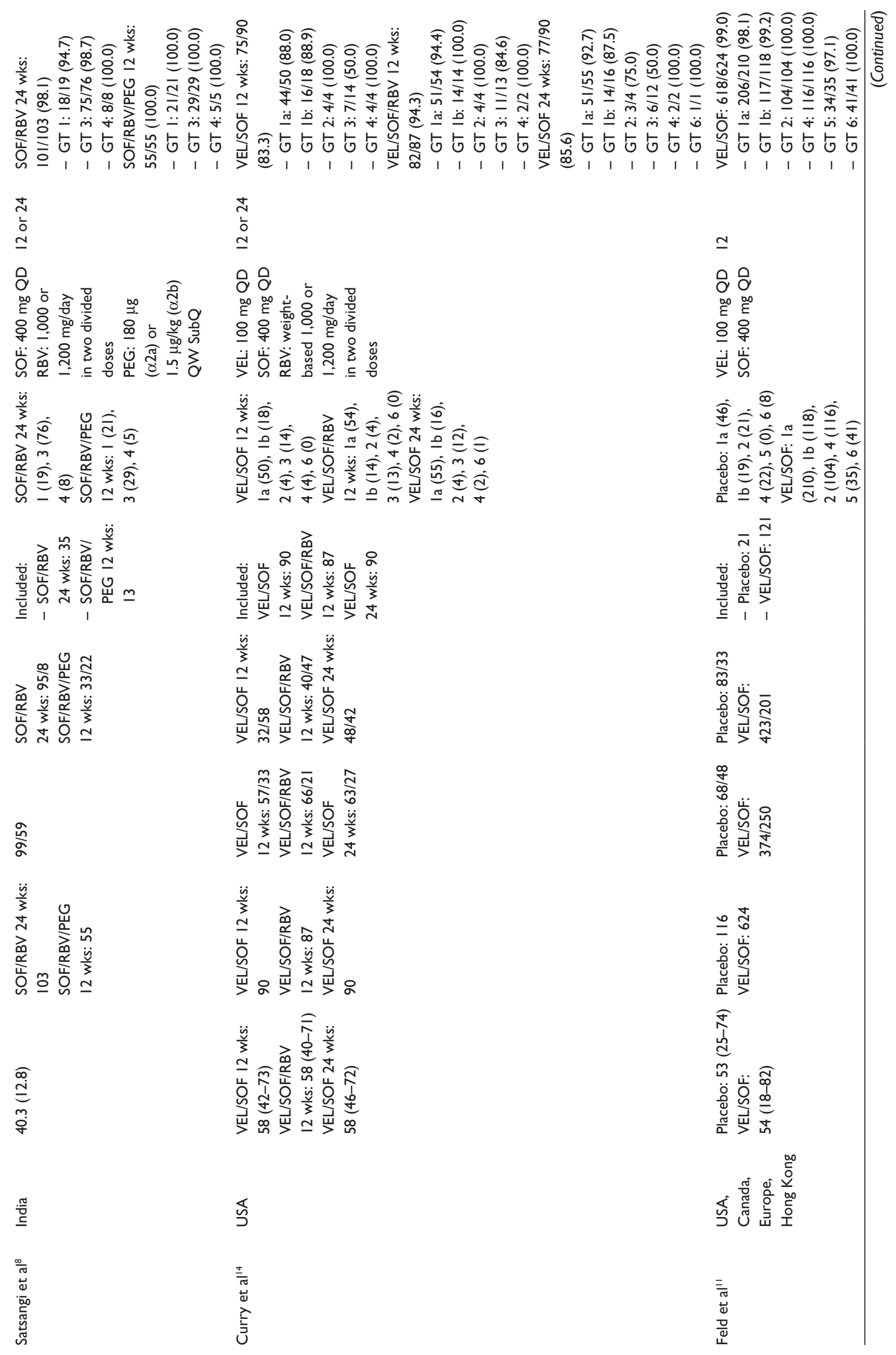




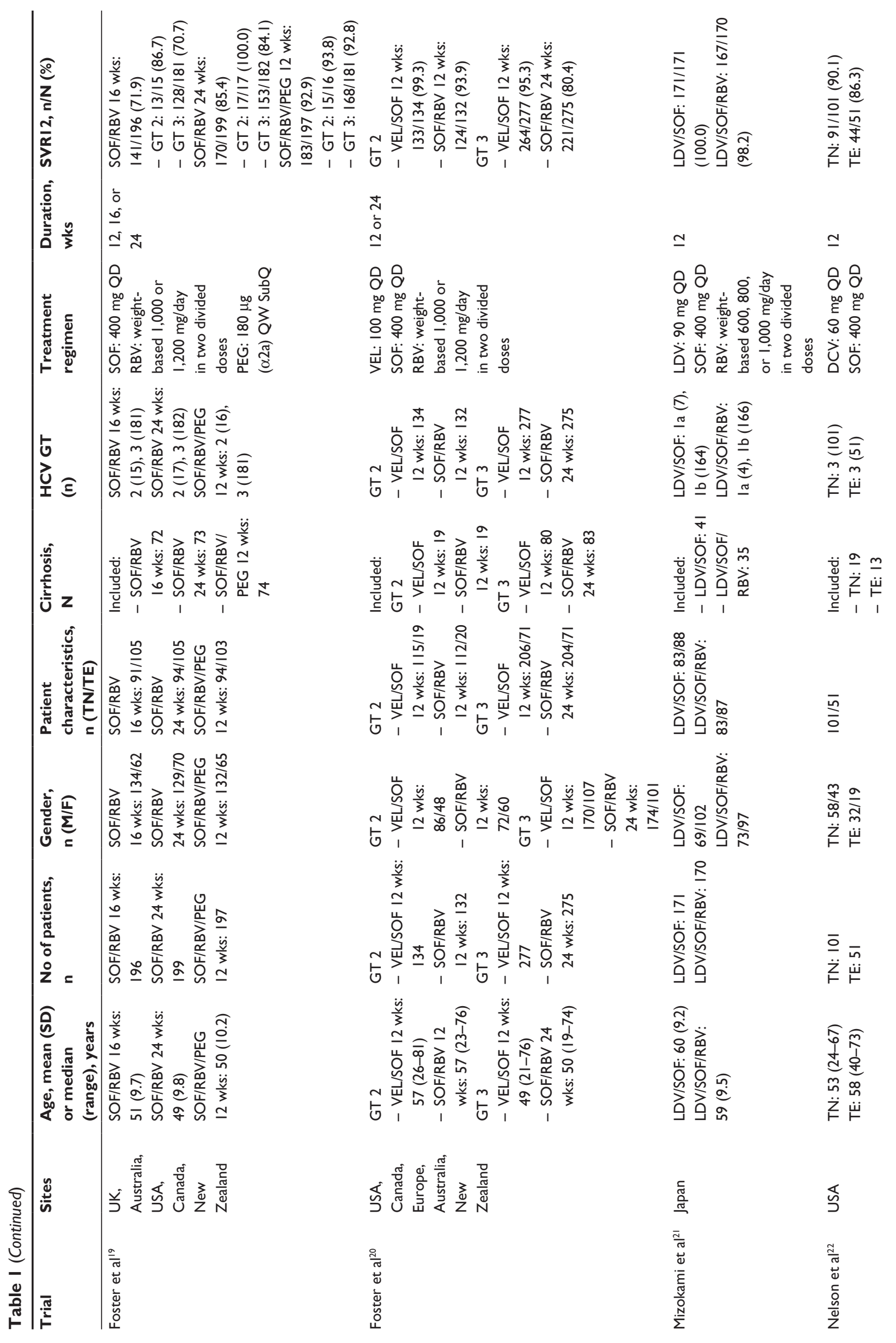




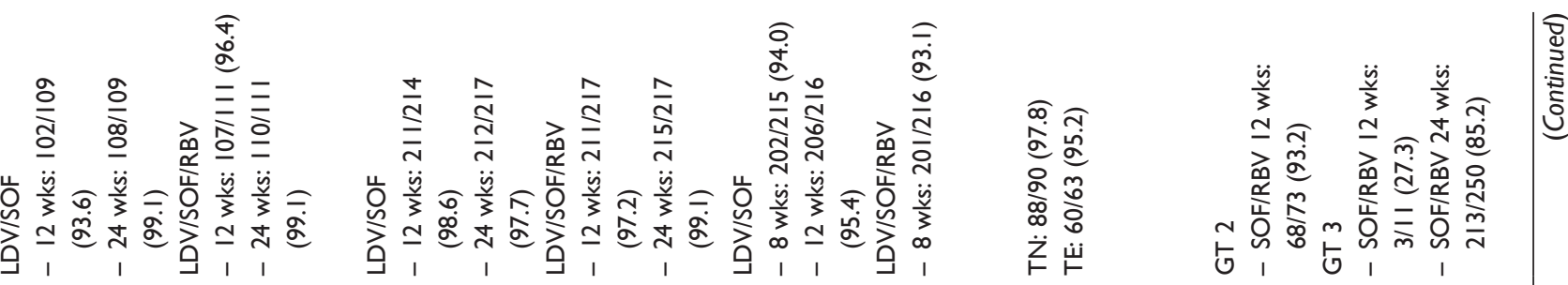

$\stackrel{\substack{ \pm \grave{0}}}{\simeq}$

요 8

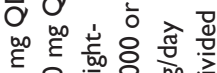

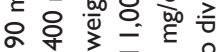

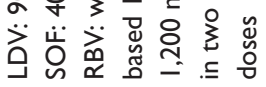

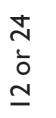

○े

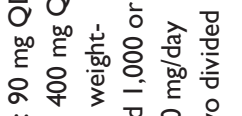

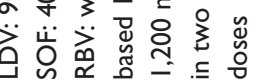

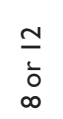

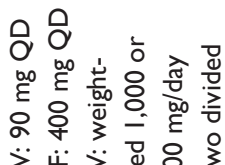

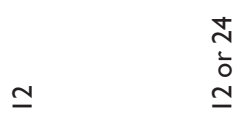

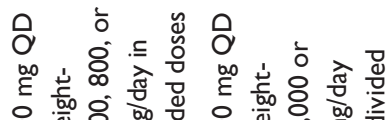

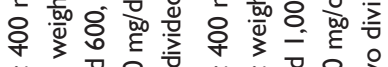

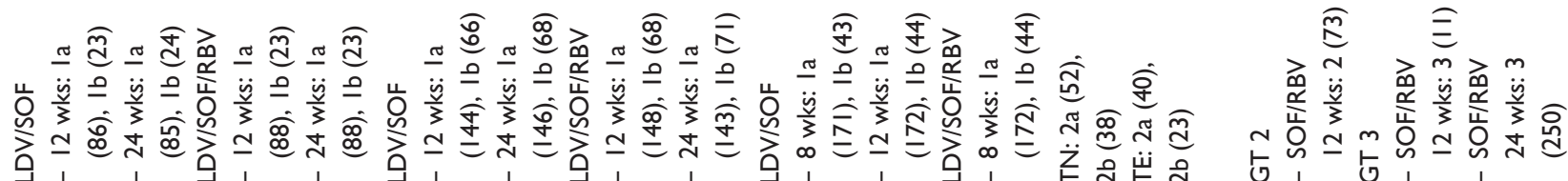

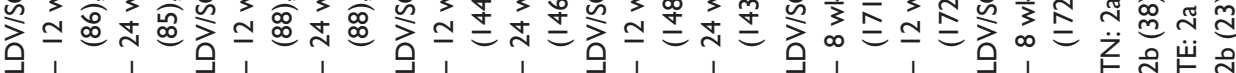

ส

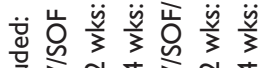

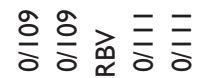

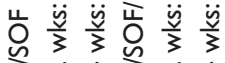

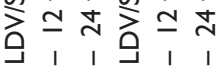

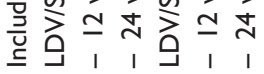

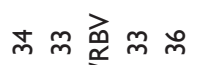

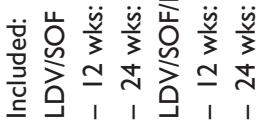

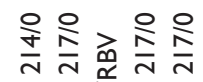

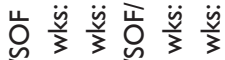

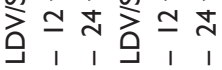

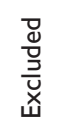

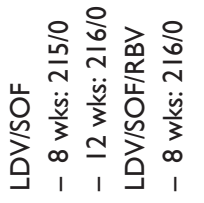

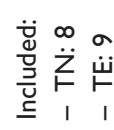

옹

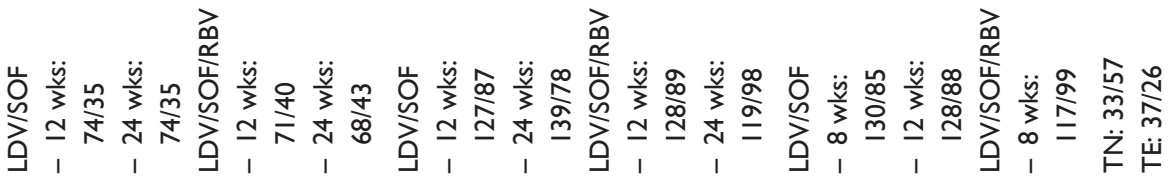

으으으믈

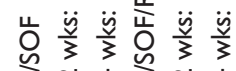

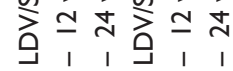

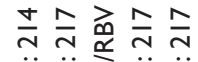

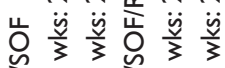

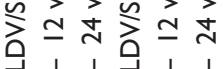

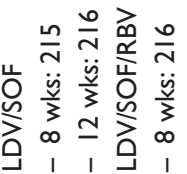

ㅇำ

$\ddot{\gtrless} \ddot{\sim}$

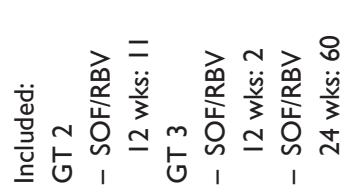
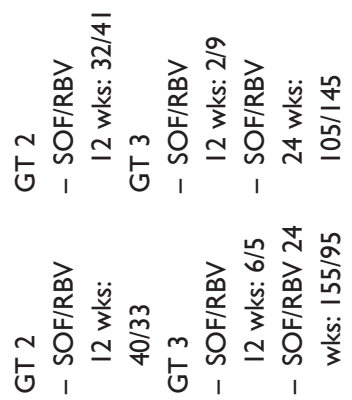

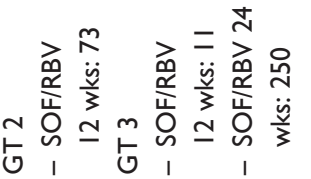

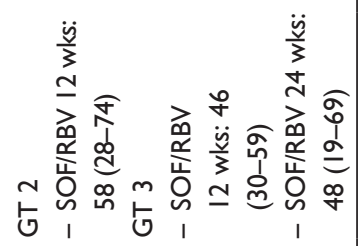

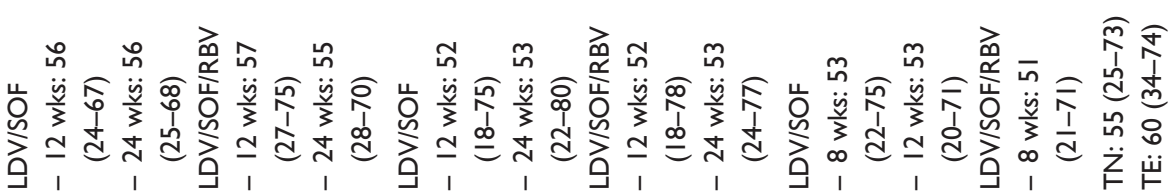

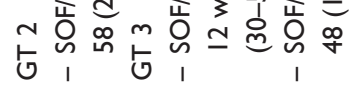

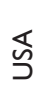

$\frac{\frac{\pi}{4}}{\frac{\pi}{0}}$

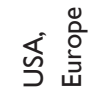

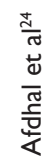

药

畜

$\frac{0}{0}$
$\frac{0}{0}$
$\frac{0}{0}$
$\frac{0}{0}$
$\frac{0}{3}$

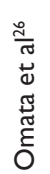

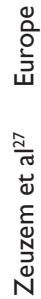




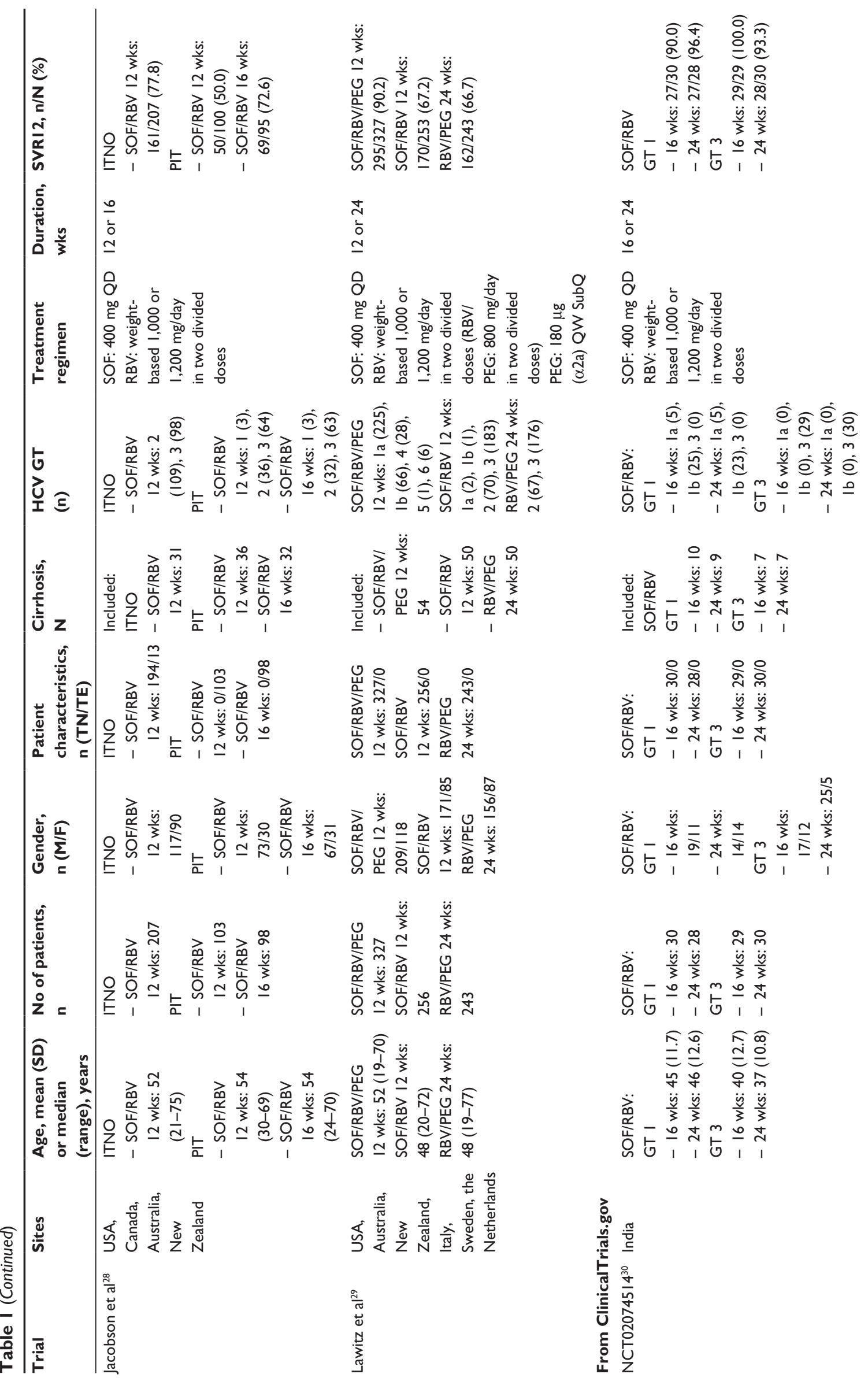




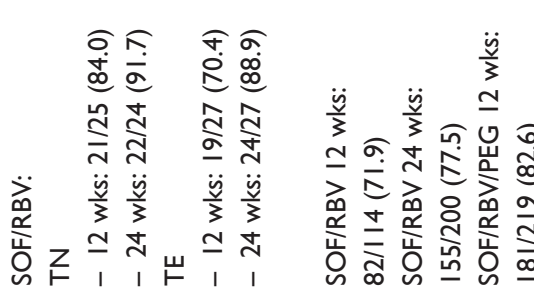

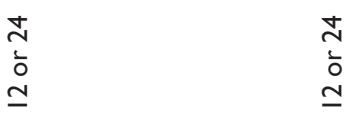

o

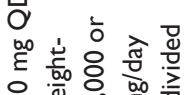

웅

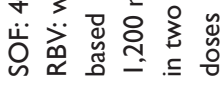

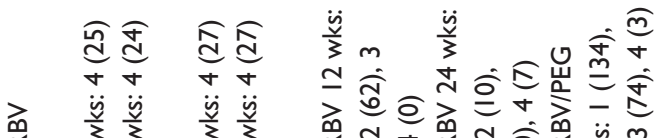

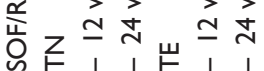

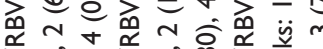

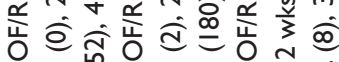

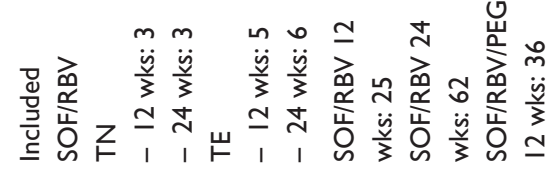

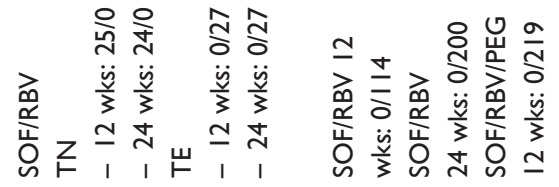

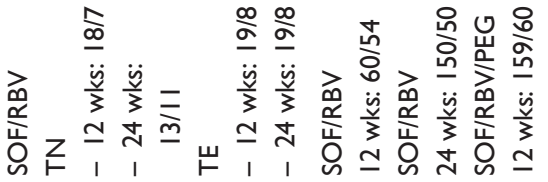

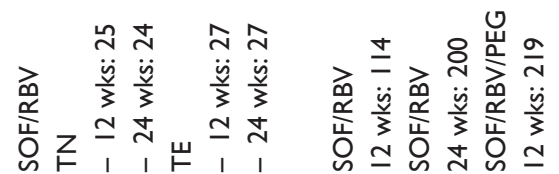

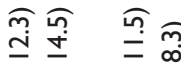

学过 for

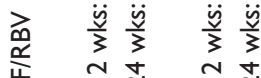

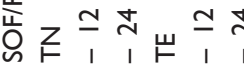

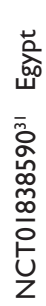

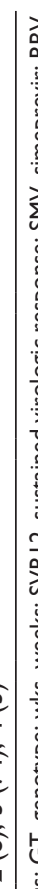

守

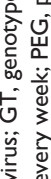

U⿺

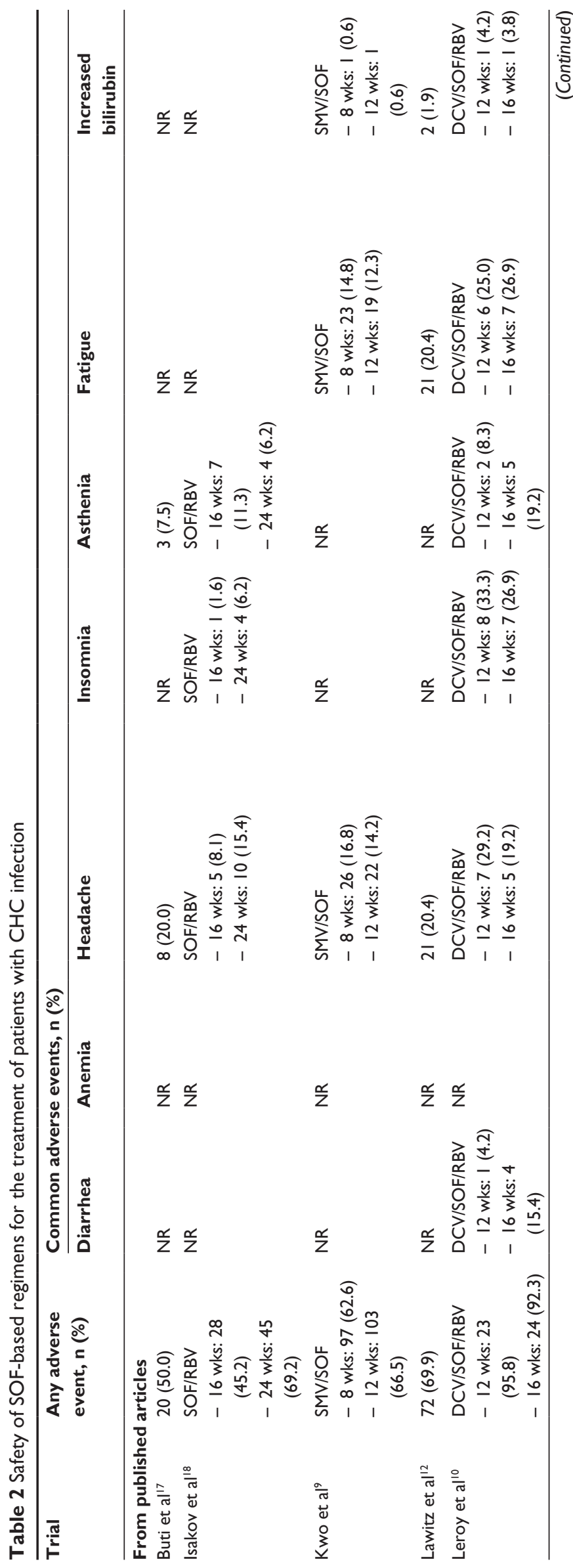




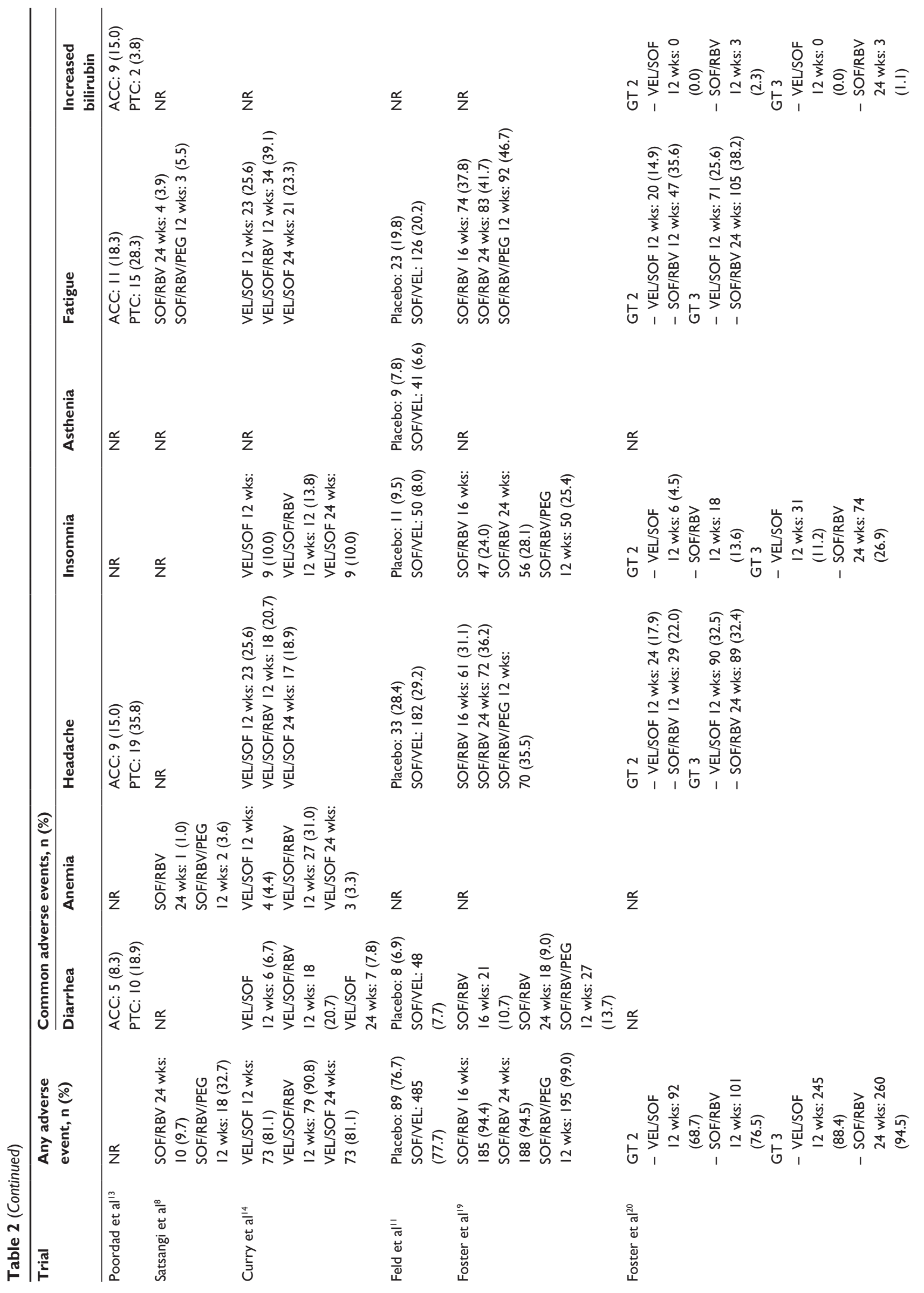




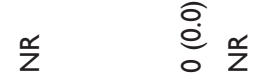

大亏

产穿在字

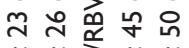

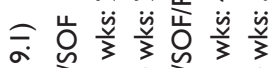

$\stackrel{o}{z}$

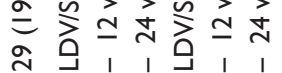

$\stackrel{o}{Z} \quad \frac{o}{z} \frac{o}{Z}$

产

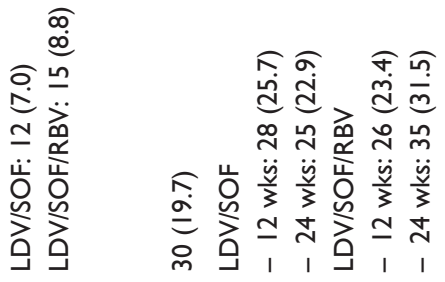

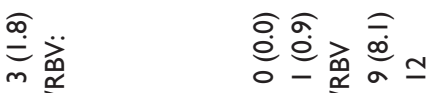

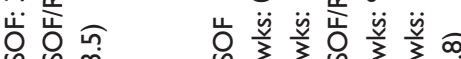

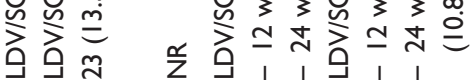

$\stackrel{\propto}{Z}$

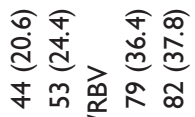

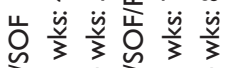

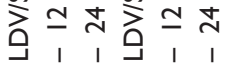

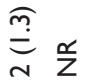

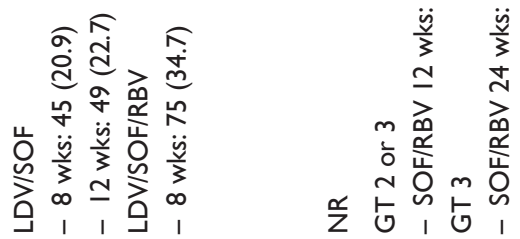

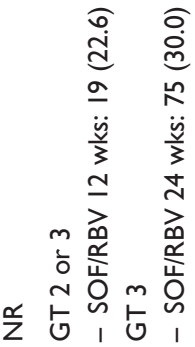

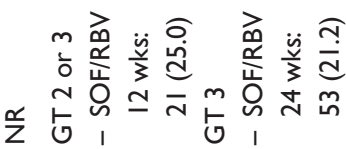

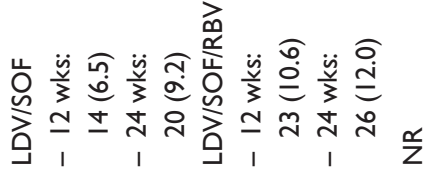

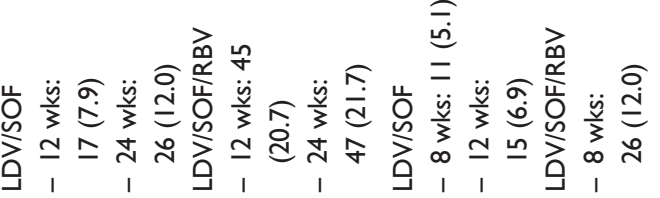

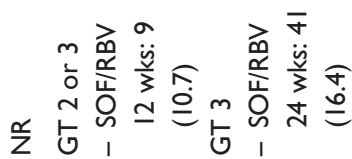

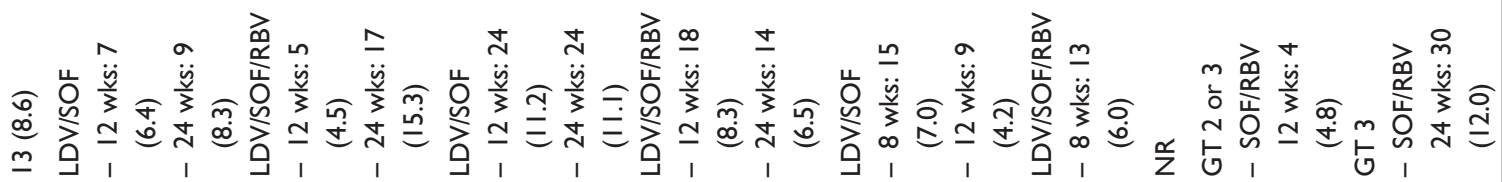

$\stackrel{\Upsilon}{Z}$

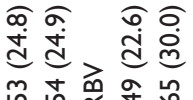

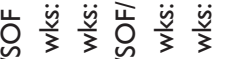

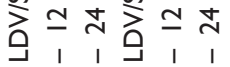

oิ่

잉에

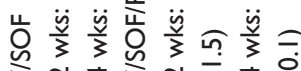

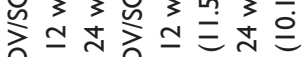

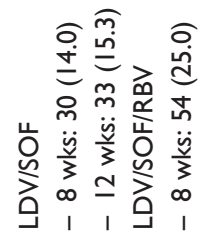

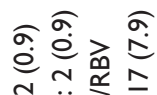

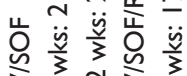

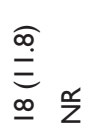

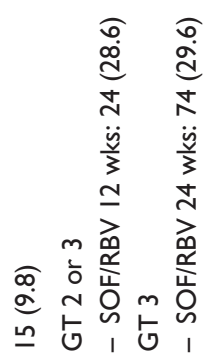

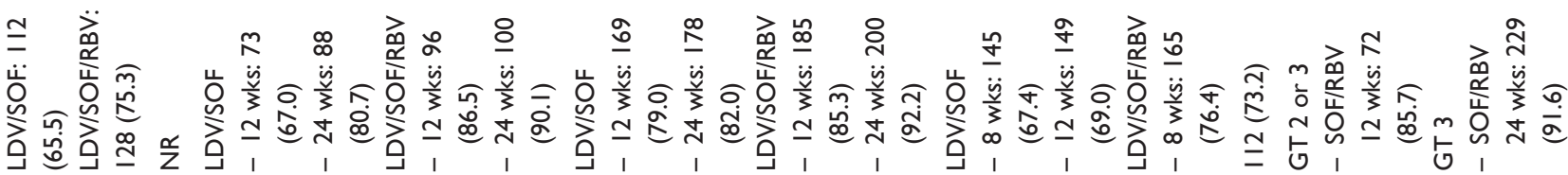
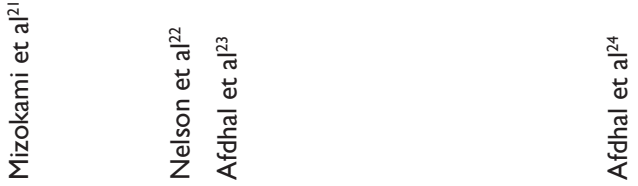

$\frac{0}{0}$
$\frac{0}{0}$
$\frac{0}{0}$
$\frac{0}{3}$
$\frac{0}{3}$

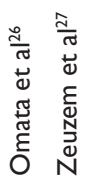




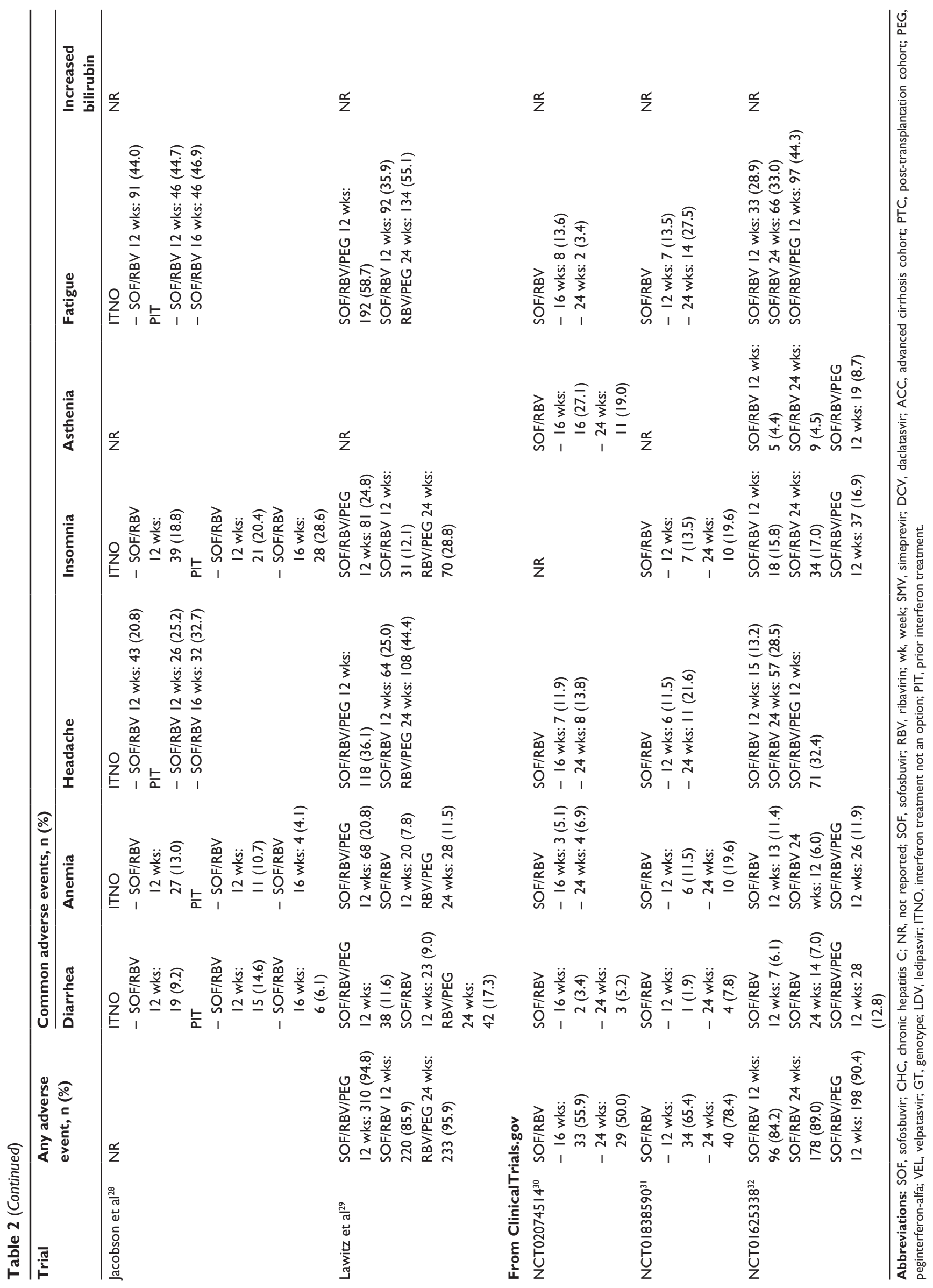


24 weeks, respectively. The rates of SVR12 were $86.4 \%$ (19 patients) and $100.0 \%$ (22 patients) among cirrhotic patients receiving LDV/SOF for 12 and 24 weeks, respectively. Among cirrhotic patients receiving LDV/SOF/RBV for 12 and 24 weeks, 18 (81.8\%) and 22 (100.0\%) patients achieved SVR12, respectively. Most patients in each treatment group experienced AEs, most of which were mild to moderate. Only among patients assigned to 24-week regimens did serious AEs occur $(6.4 \%$ in the LDV/SOF group and $2.7 \%$ in the LDV/SOF/RBV group). The incidence of AEs was higher among patients who received LDV/SOF/ RBV for 12 or 24 weeks.

In the open-label, randomized clinical trials conducted by Afdhal et $\mathrm{al}^{24}$ in the USA and Europe, 865 patients with untreated HCV genotype 1 infection were enrolled. All patients were randomly assigned to four treatment groups: LDV/SOF for 12 weeks (214 patients), LDV/ SOF for 24 weeks (217 patients), LDV/SOF/RBV for 12 weeks (217 patients), and LDV/SOF/RBV for 24 weeks (217 patients). Each patient received LDV (90 mg, once daily) and SOF (400 mg, once daily), with or without RBV (weight-based 1,000 or 1,200 mg/day in two divided doses) during the treatment period. With patients receiving LDV/ SOF for 12 and 24 weeks, $98.6 \%$ and $97.7 \%$, respectively, reached SVR12 (HCV RNA $<25 \mathrm{IU} / \mathrm{mL}$ ). Among those receiving LDV/SOF/RBV for 12 and 24 weeks, $97.2 \%$ and 99.1\%, respectively, reached SVR12. The rates of SVR12 among cirrhotic patients receiving LDV/SOF for 12 and 24 weeks were $97.0 \%$ (32 patients) and 96.9\% (31 patients), respectively. The rates of SVR12 among cirrhotic patients receiving $\mathrm{LDV} / \mathrm{SOF} / \mathrm{RBV}$ for 12 and 24 weeks were both $100.0 \%$ (33 and 36 patients, respectively). The majority of patients in all treatment groups had at least one $\mathrm{AE}$, and most AEs were mild to moderate. Of the 33 patients who experienced serious AEs, eight received 12-week regimens (one in the LDV/SOF group and seven in the LDV/SOF/ RBV group) and 25 received 24-week regimens (18 in the LDV/SOF group and seven in the LDV/SOF/RBV group). The patients who received LDV/SOF/RBV had more AEs linked to RBV therapy (eg, fatigue, insomnia, asthenia, and anemia) than those who received LDV/SOF.

An open-label, randomized clinical trial was conducted by Kowdley et $\mathrm{al}^{25}$ in the USA. A total of 647 patients with previously untreated HCV genotype 1 infection without cirrhosis were randomly assigned to three treatment groups: LDV/SOF for 8 weeks (215 patients), LDV/SOF for 12 weeks (216 patients), and LDV/SOF/RBV for 8 weeks (216 patients). The patients received LDV (90 mg, once daily) and SOF (400 mg, once daily), with and without RBV (weight-based 1,000 or 1,200 mg/day in two divided doses) during the treatment period. SVR12 (HCV RNA $<25 \mathrm{IU} / \mathrm{mL}$ ) was achieved in $94.0 \%$ of patients receiving LDV/SOF for 8 weeks, $95.4 \%$ of those receiving LDV/SOF for 12 weeks, and $93.1 \%$ of those receiving LDV/SOF/RBV for 8 weeks. The incidence of AEs was higher among patients receiving $\mathrm{LDV} / \mathrm{SOF} / \mathrm{RBV}$ for 8 weeks $(76.4 \%)$ than among those receiving LDV/SOF for 8 weeks $(67.4 \%)$ and 12 weeks (69.0\%). Grade 3 or 4 AEs occurred in two $(0.93 \%)$ patients receiving LDV/SOF for 8 weeks, seven (3.24\%) patients receiving LDV/SOF for 12 weeks, and eight (3.70\%) patients receiving LDV/SOF/RBV for 8 weeks.

\section{SOF in combination with simeprevir}

SOF was used in combination with simeprevir (SMV) in three clinical trials. In the open-label, single-arm clinical trial conducted by Buti et al ${ }^{17}$ in Spain, 40 patients with $\mathrm{HCV}$ genotype 4 infection received SMV (150 mg, once daily) plus SOF (400 mg, once daily) for 12 weeks. All patients $(100.0 \%$ ) attained SVR12 (HCV RNA $<15 \mathrm{IU} / \mathrm{mL}$ ). A total of $20(50.0 \%)$ patients reported AEs that were of grade 1 or 2 . Of 20 patients who experienced AEs, 11 were considered associated with treatment drugs. No grade $3 / 4$ or serious AEs occurred, and there were no treatment discontinuations.

In the open-label, randomized clinical study implemented by Kwo et $\mathrm{al}^{9}$ in the USA and Canada, 310 patients with HCV genotype 1 infection without cirrhosis were enrolled. The patients were randomly assigned in a 1:1 ratio to 8- or 12-week regimens and received SMV $(150 \mathrm{mg}$, once daily) and SOF (400 mg, once daily). SVR12 (HCV RNA $<25 \mathrm{IU} / \mathrm{mL}$ ) was achieved in $82.6 \%$ and $96.8 \%$ of patients in the 8 - and 12-week regimens, respectively. There was no difference in the incidence of AEs between the two treatment groups (8-week regimen, $62.6 \%$ vs 12 -week regimen, $66.5 \%$ ). Most AEs were of grade $1 / 2$. A total of seven grade 3/4 AEs occurred during the treatment period, and of them, two grade 3 AEs were possibly associated with the study treatment: increased amylase (8-week regimen) and pyelonephritis (12-week regimen). Serious AEs occurred in three patients (ie, gastroesophageal reflux disease, mania, and whiplash) and one patient (Clostridium difficile colitis) in the 8- and 12-week regimens, respectively, but none was considered linked to the study treatment.

In the open-label, single-arm clinical study by Lawitz et $\mathrm{a}^{12}$ in the USA and Canada, 103 patients with HCV genotype 1 infection and cirrhosis were enrolled. All patients received SMV (150 mg, once daily) and SOF (400 mg, once daily) for 12 weeks. SVR12 (HCV RNA $<25$ IU $/ \mathrm{mL}$ ) was attained in $83.5 \%$ of patients, and the rates of SVR 12 
were higher in $\mathrm{TN}$ than in TE patients $(88.0 \%$ vs $79.2 \%$, respectively). In all, 72 (69.9\%) patients reported AEs during the treatment, but most AEs were of grade 1 or 2 (64.1\%). Grade 3 and 4 AEs were reported in five (4.9\%) patients and one patient $(0.97 \%)$, respectively. Serious AEs occurred in five $(4.9 \%)$ patients (consisting of cellulitis, infected bite, limb injury, road traffic accident, anemia, and noncardiac chest pain), but they were not considered linked to the study treatment.

\section{SOF in combination with velpatasvir}

SOF was administered in combination with velpatasvir (VEL) in three clinical trials. In the open-label, randomized clinical study conducted by Curry et $\mathrm{al}^{14}$ in the USA, 267 patients with HCV genotype 1, 2, 3, 4, 5, or 6 infection and decompensated cirrhosis were enrolled. All patients enrolled were randomly assigned in an equal ratio to three treatment regimens: VEL/SOF for 12 weeks (90 patients), VEL/SOF/RBV for 12 weeks (87 patients), and VEL/SOF for 24 weeks (90 patients). The patients received VEL (100 mg, once daily) and SOF (400 mg, once daily), with and without RBV (weight-based 1,000 or 1,200 mg/day in two divided doses) during the treatment. SVR12 (HCV RNA < $15 \mathrm{IU} / \mathrm{mL}$ ) was achieved in $83.3 \%$ of patients receiving VEL/SOF for 12 weeks, $94.3 \%$ of patients receiving VEL/SOF/RBV for 12 weeks, and $85.6 \%$ of patients receiving VEL/SOF for 24 weeks. The incidence of AEs was higher among patients receiving VEL/SOF/RBV for 12 weeks (90.8\%) than among those receiving VEL/SOF for 12 weeks $(81.1 \%)$ or 24 weeks $(81.1 \%)$. Serious AEs occurred in $18.9 \%$ of patients who received VEL/SOF for 12 weeks, $16.1 \%$ of those who received VEL/SOF/RBV for 12 weeks, and $17.8 \%$ of those who received VEL/SOF for 24 weeks. The most common serious AEs included hepatic encephalopathy and sepsis, with each AE occurring in five patients across groups.

In the double-blind, placebo-controlled clinical study implemented by Feld et $\mathrm{al}^{11}$ in the USA, Canada, Europe, and Hong Kong, 624 and 116 patients with HCV genotype $1,2,4,5$, or 6 infection were enrolled in the VEL/SOF and placebo groups, respectively. The patients in the VEL/SOF group received VEL (100 mg, once daily) and SOF (400 mg, once daily) for 12 weeks, and those in the placebo group received a placebo tablet once daily for 12 weeks. SVR12 (HCV RNA < $15 \mathrm{IU} / \mathrm{mL}$ ) was achieved by $99.0 \%$ of patients in the treatment group, but no patient reached SVR12 in the placebo group. SVR12 was attained by 120 (99.2\%) patients with compensated cirrhosis. There was no significant difference in the incidence of AEs between the VEL/SOF group (77.7\%) and the placebo group (76.7\%). Serious AEs occurred in 15 patients who received VEL/SOF, but serious AEs were not reported in the placebo group.

Two open-label, randomized clinical studies enrolled 266 patients with HCV genotype 2 infection and 552 patients with HCV genotype 3 infection. ${ }^{20}$ The patients with $\mathrm{HCV}$ genotype 2 infection were randomly assigned in a 1:1 ratio to receive VEL/SOF for 12 weeks (134 patients) or SOF/ RBV for 12 weeks (132 patients). The patients with $\mathrm{HCV}$ genotype 3 infection were also randomly assigned in a 1:1 ratio to receive VEL/SOF for 12 weeks (277 patients) or SOF/ RBV for 24 weeks (275 patients). The patients received SOF (400 mg, once daily) with VEL (100 mg, once daily) or RBV (weight-based 1,000 or 1,200 mg/day in two divided doses) during the treatment. Among patients with HCV genotype 2, patients in the VEL/SOF group (99.3\%) showed a higher rate of SVR12 ( $\mathrm{HCV} \mathrm{RNA}<15 \mathrm{IU} / \mathrm{mL}$ ) than those in the SOF/RBV group (93.9\%) did. Among patients with $\mathrm{HCV}$ genotype 3, those in the VEL/SOF group (95.3\%) showed a higher rate of SVR12 than the patients in the SOF/RBV group $(80.4 \%)$ did. Among cirrhotic patients with HCV genotype 3, $73(91.3 \%)$ patients in the VEL/SOF group and $55(66.3 \%)$ patients in the SOF/RBV group achieved SVR12. The rate of SVR12 among cirrhotic patients with previously untreated HCV genotype 3 was $93.0 \%$ in the VEL/SOF group compared with $73.3 \%$ in the SOF/RBV group. The SVR12 rate among cirrhotic patients with previously treated $\mathrm{HCV}$ genotype 3 was $89.2 \%$ in the VEL/SOF group and $57.9 \%$ in the SOF/RBV group. In the two trials, the rates of AEs were lower among patients who received VEL/SOF than among those who received SOF/RBV. Among patients who had HCV genotype 2 infection, four patients (two in the VEL/ SOF group and two in the SOF/RBV group) experienced serious AEs. Among patients who had HCV genotype 3 infections, six patients who received VEL/SOF and 15 patients who received SOF/RBV experienced serious AEs.

\section{SOF in combination with RBV, peginterferon-alfa, or both}

A total of 10 clinical trials met the criteria for the evaluation of patients who were treated with SOF in combination with RBV, peg-IFN, or both. The open-label, randomized clinical trial was conducted by Isakov et $\mathrm{al}^{18}$ in Russia. In all, 127 patients with previously untreated HCV genotype 1 or 3 infection with and without compensated cirrhosis were randomly assigned in a 1:1 ratio to the 16- or 24-week regimens, consisting of SOF (400 mg, once daily) plus RBV (weight-based 1,000 or $1,200 \mathrm{mg} /$ day, divided into two 
doses). Among the patients with HCV genotype 1, 50.0\% and $76.5 \%$ of patients in the 16 - and 24 -week regimens, respectively, achieved SVR12 (HCV RNA <25 IU/mL). Among those with HCV genotype 3, 86.7\% and 90.3\% of patients in the 16- and 24-week regimens, respectively, achieved SVR12. Among the cirrhotic patients, patients with HCV genotype 1 tended to have lower SVR12 rates than those with HCV genotype 3, in both the 16-week treatment group $(0.0 \%$ [0/4] vs $83.3 \%$ [5/6]) and the 24 -week treatment group $(33.3 \%$ [2/6] vs $60.0 \%$ [3/5]). None of the patients discontinued the study due to AEs. No grade 3 or 4 AEs occurred, and there were no deaths. Two serious AEs (ie, pneumonia and foot fracture) occurred, but both were considered unrelated to the study treatment.

In the clinical trial conducted by Satsangi et $\mathrm{al}^{8}$ in India, 158 patients with $\mathrm{HCV}$ infection were treated with SOF (400 mg, once daily) and RBV (weight-based 1,000 or $1,200 \mathrm{mg} /$ day, divided into two doses) for 24 weeks or SOF (400 mg, once daily) with RBV (weight-based 1,000 or $1,200 \mathrm{mg} /$ day divided into two doses) and peginterferon-alfa (PEG; $180 \mu \mathrm{g}[\alpha 2 \mathrm{a}]$ or $1.5 \mu \mathrm{g} / \mathrm{kg}[\alpha 2 \mathrm{~b}]$ subcutaneously, once weekly) for 12 weeks. SVR12 was attained in $98.1 \%$ of the dual therapy group and $100.0 \%$ of the triple therapy group. Among the cirrhotic patients, 33 (94.3\%) and 13 (100.0\%) patients in the dual and triple therapy groups, respectively, achieved SVR12. AEs occurred in 10 (9.7\%) patients who received the dual therapy and $18(32.7 \%)$ patients who received the triple therapy. There were no major AEs, but anemia occurred in three patients (one in the dual therapy group and two in the triple therapy group). Five patients in the triple therapy group experienced flu-like symptoms.

The open-label, randomized clinical trials conducted by Foster et $\mathrm{al}^{19}$ in Western countries included patients with HCV genotype 2 and compensated cirrhosis, who had been previously treated with a PEG regimen for at least 12 weeks and patients with HCV genotype 3 with and without compensated cirrhosis, who were either TN or TE. A total of 592 patients were randomly assigned in an equal ratio to one of three treatment groups: SOF/RBV for 16 weeks (196 patients), SOF/RBV for 24 weeks (199 patients), and SOF/ $\mathrm{RBV} / \mathrm{PEG}$ for 12 weeks (197 patients). The patients received SOF (400 mg, once daily) and RBV (weight-based 1,000 or 1,200 mg/day, divided into two doses), with and without PEG (180 $\mu \mathrm{g}[\alpha 2 \mathrm{a}]$ subcutaneously, once weekly). SVR12 (HCV RNA $<15 \mathrm{IU} / \mathrm{mL}$ ) was reached in $71.9 \%$ of patients who received SOF/RBV for 16 weeks, $85.4 \%$ of those who received $\mathrm{SOF} / \mathrm{RBV}$ for 24 weeks, and $92.9 \%$ of those who received $\mathrm{SOF} / \mathrm{RBV} / \mathrm{PEG}$ for 12 weeks. Among the cirrhotic patients with $\mathrm{HCV}$ genotype 3, 29 (50.9\%) patients who received SOF/RBV for 16 weeks, 44 (78.6\%) patients who received SOF/RBV for 24 weeks, and 51 (87.9\%) patients who received SOF/RBV/PEG for 12 weeks attained SVR12. The majority of patients experienced at least one AE, but most AEs were mild. Across all three treatment groups, the most common AEs were fatigue, headache, and insomnia. The rate of grade 3 (moderate) or grade 4 (severe) AEs was not substantially higher in the PEG-containing group (7.6\%) than in the PEG-free groups (5.6\% and 3.5\% in those who received $\mathrm{SOF} / \mathrm{RBV}$ for 16 and 24 weeks, respectively).

In the multicenter, open-label clinical trial conducted by Omata et $\mathrm{al}^{26}$ in Japan, 153 (90 TN and $63 \mathrm{TE}$ ) patients with $\mathrm{HCV}$ genotype 2 received SOF (400 $\mathrm{mg}$, once daily) and RBV (weight-based 600, 800, 1,000 mg/day, divided into two doses) for 12 weeks. SVR12 (HCV RNA $<25 \mathrm{IU} / \mathrm{mL}$ ) was reached in $97.8 \%$ and $95.2 \%$ of patients in the TN and TE groups, respectively. SVR12 was also achieved in eight TN patients with cirrhosis $(100.0 \%)$ and eight TE patients with cirrhosis (88.9\%). At least one AE occurred in $73.2 \%$ of all patients, but the majority of AEs were mild (grade 1). No patient had a grade 4 (life-threatening) AE. Only three patients had grade 3 (severe) AEs, two of which could have been associated with the study treatment (ie, anemia and hyperbilirubinemia).

In the multicenter clinical study conducted by Zeuzem et $\mathrm{al}^{27}$ in Europe, 419 patients with HCV genotype 2 or 3 were enrolled. The patients were randomly assigned in a 4:1 ratio to either SOF/RBV regimens or matching placebo. The study was originally designed for all patients to receive 12 weeks of treatment with SOF/RBV or placebo. However, the study design was modified based on results from the FUSION phase III study. ${ }^{28}$ Accordingly, the placebo group was terminated, the patients with HCV genotype 2 were treated as planned for 12 weeks, and the treatment of patients with HCV genotype 3 was extended to 24 weeks. Among the patients with HCV genotype 3, those who had already completed 12 weeks of treatment prior to the modification of the study design were not given additional treatment. The patients received SOF (400 mg, once daily) and RBV (weight-based 1,000 or $1,200 \mathrm{mg} /$ day, divided into two doses). SVR12 (HCV RNA <25 IU/mL) was reached by 68 (93.2\%) patients with HCV genotype 2 receiving SOF/RBV for 12 weeks. SVR12 was also attained by three $(27.3 \%)$ and $213(85.2 \%)$ of patients with HCV genotype 3 receiving $\mathrm{SOF} / \mathrm{RBV}$ for 12 and 24 weeks, respectively. SVR12 was achieved by 130 (94.9\%) TN and 151 (81.2\%) TE patients. Among TN patients, 14 (93.3\%) patients with cirrhosis and 
116 (95.1\%) without cirrhosis achieved SVR12. Among TE patients, $36(64.3 \%)$ patients with cirrhosis and 115 (88.5\%) without cirrhosis achieved SVR12. At least one AE occurred in $72(85.7 \%)$ patients with SOF/RBV for 12 weeks and 229 (91.6\%) patients with SOF/RBV for 24 weeks. Nasopharyngitis, diarrhea, arthralgia, and irritability were more frequently observed in the 24-week group than in the 12-week group, but nausea was more frequently observed in the 12-week group than in the 24-week group. Serious treatment-emergent AEs occurred in two of the patients with $\mathrm{HCV}$ genotype 2 receiving SOF/RBV for 12 weeks (ie, colon adenocarcinoma and gastroenteritis) and 11 of the patients with HCV genotype 3 receiving SOF/RBV for 24 weeks (ie, increased amylase, arrhythmia, biliary colic, complex regional pain syndrome, hemorrhoidal hemorrhage, $\mathrm{HCC}$, hyperglycemia, invasive ductal breast carcinoma, increased lipase, road traffic accident, and suicide attempt).

The two multicenter, randomized clinical trials conducted by Jacobson et $\mathrm{al}^{28}$ in the USA, Canada, Australia, and New Zealand enrolled patients with chronic HCV genotype 2 or 3 infection. In one trial, 207 patients, for whom peg-IFN was not an option, received SOF (400 mg, once daily) and RBV (weight-based 1,000 or 1,200 mg/day, divided into two doses) for 12 weeks. In the other trial, 103 and 98 patients without response to prior peg-IFN treatment received the same regimen for 12 and 16 weeks, respectively. SVR12 (HCV RNA < $25 \mathrm{IU} / \mathrm{mL}$ ) was attained by $161(77.8 \%)$ patients for whom peg-IFN was not an option. Among patients without response to previous peg-IFN treatment, $50(50.0 \%)$ in the 12-week group and $69(72.6 \%)$ in the 16-week group achieved SVR12. SVR12 was realized by $19(61.3 \%)$ cirrhotic patients for whom peg-IFN was not an option. Among cirrhotic patients with no response to prior peg-IFN treatment, $11(30.6 \%)$ in the 12-week group and 21 $(65.6 \%)$ in the 16-week group attained SVR12. The most common AEs were headache, fatigue, nausea, and insomnia. Serious AEs occurred in 11 patients for whom peg-IFN was not an option. Among patients without response to prior peg-IFN treatment, five patients receiving SOF/RBV for 12 weeks and three patients receiving SOF/RBV for 16 weeks experienced serious AEs.

A single-group, open-label clinical trial enrolled 327 patients with HCV genotype 1, 4, 5, or 6, who received $\mathrm{SOF} / \mathrm{RBV} /$ peg-IFN for 12 weeks, and in a non-inferiority clinical trial, 499 patients with HCV genotype 2 or 3 were randomly assigned to receive $\mathrm{SOF} / \mathrm{RBV}$ for 12 weeks or RBV/peg-IFN for 24 weeks. ${ }^{29} \mathrm{SOF}$ (400 mg, once daily), RBV (weight-based 1,000 or 1,200 mg/day, divided into two doses), and peg-IFN (180 $\mu \mathrm{g}[\alpha 2 \mathrm{a}]$ subcutaneously, once weekly) were administered to the patients, but the dose of RBV was $800 \mathrm{mg}$ daily in two divided doses when RBV was coadministered with peg-IFN. SVR12 (HCV RNA $<25 \mathrm{IU} / \mathrm{mL}$ ) was reported in 295 (90.2\%) patients in the single-group study. In the non-inferiority trial, SVR12 was reported in $170(67.2 \%)$ patients who received SOF/ RBV and 162 (66.7\%) patients who received RBV/pegIFN. SVR12 was attained by $43(79.6 \%)$ cirrhotic patients who received SOF/RBV/peg-IFN. SVR12 was achieved by $23(46.9 \%)$ cirrhotic patients who received SOF/RBV and $19(38.0 \%)$ cirrhotic patients who received RBV/peg-IFN. At least one AE occurred in $94.8 \%, 85.9 \%$, and $95.9 \%$ of patients in the SOF/RBV/peg-IFN, SOF/RBV, and RBV/ peg-IFN groups, respectively. The most common AEs were fatigue, headache, nausea, and insomnia. Serious AEs occurred in four patients in the $\mathrm{SOF} / \mathrm{RBV} /$ peg-IFN group, seven patients in the SOF/RBV group, and three patients in the $\mathrm{RBV} /$ peg-IFN group.

In a multicenter, randomized, open-label clinical study conducted in India, 117 patients with HCV genotype 1 or 3 were enrolled. ${ }^{30}$ The enrolled patients were randomly assigned to one of four treatment groups: HCV genotype 1 and SOF/RBV for 16 weeks (30 patients), HCV genotype 1 and SOF/RBV for 24 weeks (28 patients), HCV genotype 3 and SOF/RBV for 16 weeks (29 patients), and HCV genotype 3 and SOF/RBV for 24 weeks (30 patients). The patients received SOF (400 mg, once daily) and RBV (weight-based 1,000 or 1,200 mg/day, divided into two doses). SVR12 (HCV RNA $<15 \mathrm{IU} / \mathrm{mL}$ ) was reported in $90.0 \%$ and $96.4 \%$ of patients with HCV genotype 1 in the 16- and 24-week groups, respectively. SVR12 was also achieved in $100.0 \%$ and $93.3 \%$ of patients with $\mathrm{HCV}$ genotype 3 in the 16- and 24-week groups, respectively. AEs (not including serious AEs) occurred in $32(54.2 \%)$ patients receiving SOF/RBV for 16 weeks and 27 (46.6\%) patients receiving $\mathrm{SOF} / \mathrm{RBV}$ for 24 weeks. The most common AEs were asthenia, fatigue, headache, and cough. Serious AEs occurred in one patient in the 16-week group and one patient in the 24-week group.

In a randomized, open-label clinical study conducted in Egypt, 103 patients with HCV genotype 4 were enrolled. ${ }^{31}$ The enrolled patients were randomly assigned to one of four treatment groups: $\mathrm{TN}$ and $\mathrm{SOF} / \mathrm{RBV}$ for 12 weeks (25 patients), TE and SOF/RBV for 12 weeks (27 patients), $\mathrm{TN}$ and SOF/RBV for 24 weeks (24 patients), and TE and $\mathrm{SOF} / \mathrm{RBV}$ for 24 weeks (27 patients). The patients received SOF (400 mg, once daily) and RBV (weight-based 1,000 
or 1,200 mg/day, divided into two doses). SVR12 (HCV RNA $<25 \mathrm{IU} / \mathrm{mL}$ ) was reported in $84.0 \%$ and $70.4 \%$ of TN and TE patients, respectively, in the 12-week group. SVR12 was also achieved in $91.7 \%$ and $88.9 \%$ of TN and TE patients, respectively, in the 24-week group. AEs (not including serious AEs) occurred in $34(65.4 \%)$ patients receiving SOF/ RBV for 12 weeks and 38 (74.5\%) patients receiving SOF/ RBV for 24 weeks. The most common AEs were insomnia, headache, fatigue, and anemia. No patients in the 12-week group had serious AEs, but two patients in the 24-week group experienced serious AEs (ie, cerebral ischemia and dyspnea).

In an open-label clinical study conducted in North America, Europe, Australia, and New Zealand, 534 patients with HCV infection were enrolled. ${ }^{32}$ The enrolled patients received one of three treatment regimens: SOF/RBV for 12 weeks (114 patients), SOF/RBV for 24 weeks (200 patients), and SOF/ $\mathrm{RBV} /$ peg-IFN for 12 weeks (220 patients). The patients received SOF (400 $\mathrm{mg}$, once daily) and RBV (weightbased 1,000 or $1,200 \mathrm{mg} /$ day, divided into two doses), with or without peg-IFN (180 $\mu \mathrm{g}[\alpha 2 \mathrm{a}]$ subcutaneously, once weekly). SVR12 (HCV RNA $<25 \mathrm{IU} / \mathrm{mL}$ ) was attained by $71.9 \%$ of patients who received $\mathrm{SOF} / \mathrm{RBV}$ for 12 weeks, $77.5 \%$ of patients who received $\mathrm{SOF} / \mathrm{RBV}$ for 24 weeks, and $82.6 \%$ of patients who received $\mathrm{SOF} / \mathrm{RBV} /$ peg-IFN for 12 weeks. AEs (not including serious AEs) occurred in $92(80.7 \%)$ patients receiving SOF/RBV for 12 weeks, 167 $(83.5 \%)$ patients receiving SOF/RBV for 24 weeks, and 194 (88.6\%) patients receiving SOF/RBV/peg-IFN for 12 weeks. The most common AEs were anemia, nausea, fatigue, arthralgia, headache, insomnia, irritability, cough, pruritus, and rash. Serious AEs occurred in four patients receiving SOF/RBV for 12 weeks, 11 patients receiving SOF/RBV for 24 weeks, and four patients receiving SOF/RBV/peg-IFN for 12 weeks.

\section{Discussion}

The present study is the first attempt to review the literature and provide a comprehensive summary of the efficacy and safety of SOF-based regimens for the treatment of patients with chronic $\mathrm{HCV}$ infection. The results indicate that the rates of SVR12 were high when SOF-based regimens were administered to $\mathrm{HCV}$-infected patients. In particular, oral peg-IFN-free regimens, consisting of at least two DAAs that included SOF, provided higher rates of SVR12 than those from regimens using SOF, RBV, or peg-IFN without other DAAs. The SOF-based regimens were also relatively safe. The safety profile of SOF improved when coadministered with other DAAs (ie, DCV, LDV, SMV, and VEL) than with
RBV and peg-IFN. Most AEs experienced by patients who received SOF with other DAAs were mild to moderate.

For $>20$ years, the combination of RBV and peg-IFN has been used as the standard of treatment for $\mathrm{HCV}$-infected patients by boosting their immune systems. ${ }^{33}$ This regimen has caused unfavorable efficacy and safety profiles in the treatment of HCV infections. ${ }^{34}$ However, with the advent of DAAs, the field of HCV treatment has dramatically changed. This evolution allows HCV-infected patients to be treated only with oral medications. If the improved antiviral potency and safety profiles of oral peg-IFN-free regimens can be demonstrated, combinations of DAAs may become the standard of treatment for $\mathrm{HCV}$ infections, because these regimens can be patient optimized, depending on disease progression, $\mathrm{HCV}$ genotype, and prior HCV treatment history. ${ }^{35}$

The clinical trials reviewed in this study demonstrate that SOF/DCV with or without RBV have the potential to manage $\mathrm{HCV}$-infected patients, especially those with $\mathrm{HCV}$ genotype 1 or $3 .{ }^{10,13,22}$ When SOF/DCV was administered to $\mathrm{TN}$ and $\mathrm{TE}$ patients with $\mathrm{HCV}$ infection, the overall rate of SVR12 was higher in TN patients than in TE patients. However, when SOF/DCV was administered to cirrhotic patients with $\mathrm{HCV}$ infection, the rate of SVR12 was higher in TE patients than in TN patients. ${ }^{22}$ Additionally, although it may be difficult to accurately compare the rates of SVR12 due to background differences among study patients in the three clinical trials, ${ }^{10,13,22}$ there were no differences in SVR12 between RBV-free and RBV-containing regimens. Thus, $\mathrm{RBV}$ is unlikely to be required as an adjunct therapy with SOF/DCV and may be detrimental, considering the risk of AEs that are associated with RBV, such as hemolytic anemia, pruritus, rash, fatigue, and teratogenicity. ${ }^{36}$

In this study, the efficacy and safety of SOF/LDV with or without RBV were assessed. Regarding the duration of treatment, the rates of SVR12 were similar in patients who received 8,12 , or 24 weeks of treatment in the SOF/LDV and SOF/LDV/RBV groups. ${ }^{21,23-25}$ With the extension of treatment to 12 or 24 weeks, additional benefits were not linked with the inclusion of RBV in the SOF/LDV regimen. Thus, as demonstrated in the previous reviews, the 12- or 24-week SOF/LDV regimen should adequately treat most patients with HCV genotype 1 infection, considering the risk of AEs from RBV use..$^{33,36,37}$ However, the 8-week $\mathrm{SOF} / \mathrm{LDV}$ regimen should also be considered carefully in certain patients, because a reduction in the treatment duration may lead to lower treatment costs. The addition of RBV to the $\mathrm{SOF} / \mathrm{LDV}$ regimen could not improve the rates of SVR12 in cirrhotic patients, which were independent of the 
duration of treatment. ${ }^{23,24}$ A similar trend was also shown in cirrhotic patients, irrespective of the therapeutic history (ie, TN vs TE). ${ }^{21}$ Although several unmet needs should still be addressed, the combination of SOF/LDV can be utilized in difficult-to-treat patients, including those who have cirrhotic symptoms.

When the SOF/SMV regimen was administered to patients with HCV genotype 1 infection without cirrhosis for 12 weeks, the rate of SVR12 was $96.8 \% .{ }^{9}$ However, when the same regimen was administered to cirrhotic patients with HCV genotype 1 infection for 12 weeks, the rate of SVR12 was $83.5 \% .^{12}$ Therefore, the SOF/SMV regimen may be beneficial for patients with HCV genotype 1 infection and no cirrhosis, but this regimen has to be carefully considered in cirrhotic patients with HCV genotype 1. The 12- or 24-week $\mathrm{SOF} / \mathrm{LDV}$ regimen may be one possible treatment option for this group. Additionally, according to the World Health Organization (WHO) guidelines published in April 2016, if an HCV genotype 1a-infected patient has the Q80K polymorphism, this regimen should not be considered. ${ }^{7}$

The clinical trials reviewed in this study indicate that the SOF/VEL regimen was effective for the treatment of patients with HCV genotype 1, 2, 3, 4, 5, or 6 infection. ${ }^{11,14,20}$ In particular, this regimen had high SVR12 rates of $99.3 \%$ for HCV genotype 2 patients and 95.3\% for HCV genotype 3 patients. ${ }^{20}$ This regimen was highly effective in patients with compensated cirrhosis. ${ }^{11}$ The addition of RBV to this regimen also improved the rate of SVR12 in patients with decompensated cirrhosis. ${ }^{14}$ The SOF/VEL regimen was recently approved as a fixed-dose combination pill, called Epclusa ${ }^{\circledR}$, in the USA. As shown in the results from the clinical study, ${ }^{20}$ this regimen was beneficial for patients with HCV genotype 3 infections, who had no effective therapeutic options until approval of this medication. ${ }^{38}$ It is also possible that this DAA combination could safely and effectively cure patients with decompensated cirrhosis, irrespective of HCV genotypes. Consequently, this pan-genotypic DAA regimen may be a highly effective antiviral therapy that minimizes laboratory testing to identify HCV genotypes before initiating treatment to optimize therapeutic outcomes.

In this study, the efficacy and safety of SOF with RBV, peg-IFN, or both were evaluated. Dual treatment with SOF/ RBV for 16 or 24 weeks was associated with relatively high SVR12 rates in HCV-infected patients. ${ }^{8,18,19,27,30,31}$ In particular, dual therapy with SOF/RBV for 24 weeks showed similar efficacy to the triple therapy with SOF/RBV/peg-IFN for 12 weeks. ${ }^{8,19,32}$ Patients with HCV genotype 3 infection showed lower SVR12 rates than those with HCV genotype 2 infection. ${ }^{39}$ It was reported that, when compared to patients with HCV genotype 2 infection, those with HCV genotype 3 infection benefited when the administration of SOF/RBV was extended to 24 weeks. ${ }^{27}$ Additionally, among patients with $\mathrm{HCV}$ genotype 3 infection, including a large proportion of TE patients with compensated cirrhosis, SOF/RBV/peg-IFN treatment for 12 weeks produced higher SVR12 rates than did SOF/RBV treatment for 16 or 24 weeks. ${ }^{19}$ Thus, the 24 -week $\mathrm{SOF} / \mathrm{RBV}$ regimen could be recommended for patients with $\mathrm{HCV}$ genotype 3 infection. For cirrhotic patients with $\mathrm{HCV}$ genotype 3 infections, the 12-week SOF/RBV/peg-IFN could be considered an alternative treatment option when accessing SOF-based regimens, including other DAAs, is difficult. However, the use of this regimen for cirrhotic patients with HCV genotype 3 infections has to be decided based on the risk-benefit ratio of its poor safety profile and quality of life versus the reduction in treatment costs, because peg-IFN is associated with various AEs, including flu-like symptoms, depression, anemia, and thyroid dysfunction. ${ }^{40}$

Now that several DAAs have been approved in Europe and the USA, HCV infection could possibly become a curable disease. However, each DAA has its own metabolic pathways and DDIs; therefore, managing DDIs before they occur is important to provide better antiviral potency, improved safety, and increased drug adherence. Most DDIs are associated with metabolism, especially by CYP3A4 and hepatic/intestinal transporters, such as organic aniontransporting polypeptide and P-gp. ${ }^{15}$ Based on data found in Micromedex ${ }^{\circledR}$ Solutions, which is a drug information database, the major DDIs between DAAs and other drugs are summarized in Table 3. As shown in the table, DDIs usually occur in patients who receive DCV, SMV, SOF, and VEL, because they are inducers and/or inhibitors of CYP3A4 and/or P-gp. DCV is contraindicated when used with strong CYP3A4 inducers (eg, phenytoin, carbamazepine, rifampin, and St John's wort) because of the risk of loss of DCV efficacy. The coadministration of SMV and cyclosporine may lead to increased cyclosporine exposure, possibly resulting in AEs. The risk of bradycardia increases in patients who receive amiodarone with DAAs. Specifically, when combination regimens are used, significant DDIs for $\mathrm{SOF} / \mathrm{RBV}, \mathrm{SOF} / \mathrm{SMV}, \mathrm{SOF} / \mathrm{DCV}$, and SOF/LDV could be expected in $9.6 \%, 31.4 \%, 36.8 \%$, and $40.2 \%$ of patients, respectively. ${ }^{41}$ Elderly patients are frequently exposed to the risks of DDIs associated with DAAs because of increased polypharmacy. In the clinical study by Vermehren et $\mathrm{al}^{42}$ in Germany, HCV-infected patients aged $\geq 65$ years took significantly more concomitant drugs, compared with those 
Table 3 Examples of DDIs between DAAs and other drugs

\begin{tabular}{|c|c|c|c|c|}
\hline Drug & Interaction drug & Severity ${ }^{a}$ & $\begin{array}{l}\text { Quality of } \\
\text { evidence }^{\text {b }}\end{array}$ & Summary \\
\hline \multirow[t]{6}{*}{$\mathrm{DCV}$} & $\begin{array}{l}\text { Strong CYP3A4 inducers (eg, phenytoin, } \\
\text { carbamazepine, rifampin, St John's wort) }\end{array}$ & Contraindicated & Fair & $\begin{array}{l}\text { Decreased DCV exposure and risk of loss of } \\
\text { DCV efficacy }\end{array}$ \\
\hline & $\begin{array}{l}\text { Strong CYP3A4 inhibitors (eg, ketoconazole, } \\
\text { clarithromycin, itraconazole, voriconazole, } \\
\text { grapefruit juice) }\end{array}$ & Major & Fair & Increased DCV exposure \\
\hline & Digoxin & Major & Good & Increased digoxin concentration \\
\hline & Cobicistat & Major & Fair & Increased DCV concentration \\
\hline & Amiodarone & Major & Fair & Increased risk of bradycardia \\
\hline & Etravirine & Major & Fair & Decreased DCV concentration \\
\hline \multirow[t]{8}{*}{ LDV } & Rosuvastatin & Major & Fair & Increased rosuvastatin exposure \\
\hline & $\begin{array}{l}\text { Proton pump inhibitors (eg, omeprazole, } \\
\text { lansoprazole, pantoprazole, rabeprazole, } \\
\text { esomeprazole) }\end{array}$ & Major & Fair & Decreased LDV exposure and loss of efficacy \\
\hline & Amiodarone & Major & Fair & Increased risk of bradycardia \\
\hline & Digoxin & Major & Fair & Increased digoxin concentration \\
\hline & Tenofovir disoproxil fumarate & Major & Fair & Increased tenofovir concentration \\
\hline & $\begin{array}{l}\text { Anticonvulsants (eg, phenytoin, phenobarbital, } \\
\text { oxcarbazepine, fosphenytoin) }\end{array}$ & Major & Fair & Decreased LDV exposure and loss of efficacy \\
\hline & Antimycobacterials (eg, rifabutin, rifapentine) & Major & Fair & Decreased LDV exposure and loss of efficacy \\
\hline & $\begin{array}{l}\text { Antacids (eg, calcium carbonate, magnesium } \\
\text { carbonate, sodium bicarbonate) }\end{array}$ & Major & Fair & Decreased LDV exposure and loss of efficacy \\
\hline \multirow[t]{6}{*}{ SMV } & Cyclosporine & Major & Excellent & Increased cyclosporine exposure \\
\hline & Atorvastatin, rosuvastatin, simvastatin & Major & Excellent & $\begin{array}{l}\text { Increased atorvastatin, rosuvastatin, and } \\
\text { simvastatin exposure }\end{array}$ \\
\hline & Digoxin & Major & Excellent & Increased digoxin exposure \\
\hline & $\begin{array}{l}\text { Moderate/strong CYP3A4 inhibitors } \\
\text { (eg, ketoconazole, clarithromycin, itraconazole, } \\
\text { voriconazole, grapefruit juice) }\end{array}$ & Major & Fair & Increased SMV exposure \\
\hline & Amiodarone & Major & Fair & Increased risk of bradycardia \\
\hline & Diltiazem, verapamil & Major & Fair & $\begin{array}{l}\text { Increased exposure of diltiazem, verapamil, } \\
\text { and SMV }\end{array}$ \\
\hline \multirow[t]{3}{*}{ SOF } & Amiodarone & Major & Fair & Increased risk of bradycardia \\
\hline & $\begin{array}{l}\text { Dual CYP3A4 and P-gP inducers (eg, carbamazepine, } \\
\text { rifampin, St John's wort) }\end{array}$ & Major & Fair & Decreased SOF exposure \\
\hline & $\begin{array}{l}\text { Moderate/strong inducers of CYP3A4, CYP2C8, or } \\
\text { CYP2B6 (eg, phenytoin, phenobarbital, mitotane, } \\
\text { rifabutin, oxcarbazepine) }\end{array}$ & Major & Fair & Decreased SOF exposure \\
\hline \multirow[t]{6}{*}{ VEL } & $\begin{array}{l}\text { Proton pump inhibitors (eg, omeprazole, } \\
\text { lansoprazole, pantoprazole, rabeprazole, } \\
\text { esomeprazole) }\end{array}$ & Major & Fair & Decreased VEL exposure \\
\hline & $\begin{array}{l}\text { Dual CYP3A4 and P-gP inducers (eg, carbamazepine, } \\
\text { rifampin, St John's wort) }\end{array}$ & Major & Fair & Decreased VEL exposure \\
\hline & $\begin{array}{l}\text { Moderate/strong inducers of CYP3A4, CYP2C8, or } \\
\text { CYP2B6 (eg, phenytoin, phenobarbital, mitotane, } \\
\text { rifabutin, oxcarbazepine) }\end{array}$ & Major & Fair & Decreased VEL exposure \\
\hline & Digoxin & Moderate & Good & Increased digoxin concentration \\
\hline & $\begin{array}{l}\text { Histamine } \mathrm{H}_{2} \text { antagonists (eg, cimetidine, ranitidine, } \\
\text { famotidine, nizatidine) }\end{array}$ & Moderate & Fair & Decreased VEL exposure \\
\hline & $\begin{array}{l}\text { Antacids (eg, calcium carbonate, magnesium } \\
\text { carbonate, sodium bicarbonate) }\end{array}$ & Moderate & Fair & Decreased VEL exposure \\
\hline
\end{tabular}

Notes: a Contraindicated - the drugs are contraindicated for concurrent use; Major - the interaction may be life-threatening and/or need medical intervention to minimize or prevent serious AEs; Moderate - the interaction may exacerbate the patient's condition and/or need an alternative therapy; Minor - the interaction may cause an increase in the frequency or severity of side effects but would not need a major alternative therapy; and Unknown - unknown. ${ }^{b}$ Excellent - the existence of the interaction has clearly been established through controlled studies; Good - the existence of the interaction is strongly suggested through documentation, but well-controlled studies are rare; Fair available documentation is poor, but pharmacologic concerns lead clinicians to suspect that the existence of the interaction or documentation regarding pharmacologically similar drug is good; and Unknown - unknown.

Abbreviations: DDI, drug-drug interaction; DAA, direct-acting antiviral; DCV, daclatasvir; LDV, ledipasvir; SMV, simeprevir; SOF, sofosbuvir; P-gP, P-glycoprotein; VEL, velpatasvir. 
aged $<65$ years ( $79 \%$ vs $51 \%, P<0.0001$ ); HCV-infected patients with cirrhosis aged $\geq 65$ years took the highest number of concomitant drugs per patient. Additionally, the proportion of predicted DDIs, using the Hep-Drug Interactions database, was significantly higher in elderly patients with $\mathrm{HCV}$ infection, compared to that of their counterparts (54\% vs $28 \%, P<0.0001){ }^{42}$

This study had some limitations that must be addressed. Only two electronic databases (ie, PubMed and ClinicalTrials. gov) were searched to identify relevant clinical trials, although there were other databases available. This limited database use could have restricted our ability to find additional valuable and relevant clinical trials. Almost all the selected clinical trials mentioned that SOF-based combination treatments were effective and safe. However, the results were usually obtained from clinical trials of Western populations, which could lead to inconclusive results regarding the efficacy and safety of SOF-based regimens in Asian populations. In addition, although the prevalence of $\mathrm{HCV}$ infection is highest in Asia, access to peg-IFN-free regimens may be difficult in Asian countries. Furthermore, peg-IFN-based regimens may be a treatment option for $\mathrm{HCV}$ infection only in some Asian countries. ${ }^{43}$ Therefore, there is still a need for more clinical studies with Asian populations in order to improve current practices in the management of HCV infection in Asia. Most of the presented studies did not mention DAA-associated DDIs and drug-disease interactions, which could occur in real clinical settings. Thus, future clinical studies are necessary to determine the safety of DAAs with regard to DDIs and drug-disease interactions.

\section{Conclusion}

The clinical trials reviewed in this study suggest that SOFbased treatment regimens for $\mathrm{HCV}$-infected patients with or without cirrhosis can be effective and safe patient-convenient medications. However, it is necessary to monitor HCVinfected patients, since rare AEs, DDIs, and drug-disease interactions can occur in real clinical settings. Most of the reviewed clinical trials were conducted in Western countries where clinical practice conditions differ from those in Asian countries. Therefore, well-designed, prospective, large-scale, randomized clinical trials are necessary to determine the efficacy and safety of SOF-based regimens for the treatment of HCV-infected patients, considering current clinical practice conditions in Asian countries. In addition, studies of management strategies for HCV-infected patients with advanced age, renal impairment, or liver transplantation are also necessary in the near future.

\section{Acknowledgment}

This work was supported by the National Research Foundation of Korea (NRF) grant funded by the Korea government (No 2016R1C1B1015938).

\section{Disclosure}

The authors report no conflicts of interest in this work.

\section{References}

1. Gower E, Estes C, Blach S, Razavi-Shearer K, Razavi H. Global epidemiology and genotype distribution of the hepatitis $\mathrm{C}$ virus infection. $J$ Hepatol. 2014;61(1 suppl):S45-S57.

2. Médecins du Monde. New Treatments for Hepatitis C Virus: Strategies for Achieving Universal Access; 2014. Available from: http:/hepcoalition.org/ IMG/pdf/web_daas_strategies_for_achieving_universal_access_en.pdf. Accessed December 14, 2016.

3. Ahmad T, Yin P, Saffitz J, et al. Cardiac dysfunction associated with a nucleotide polymerase inhibitor for treatment of hepatitis C. Hepatology. 2015;62(2):409-416.

4. Weiler N, Zeuzem S, Welker MW. Concise review: interferon-free treatment of hepatitis $\mathrm{C}$ virus-associated cirrhosis and liver graft infection. World J Gastroenterol. 2016;22(41):9044-9056.

5. Han DS, Hahm B, Rho HM, Jang SK. Identification of the protease domain in NS3 of hepatitis C virus. J Gen Virol. 1995;76(pt 4): 985-993.

6. Welzel TM, Dultz G, Zeuzem S. Interferon-free antiviral combination therapies without nucleosidic polymerase inhibitors. $J$ Hepatol. 2014;61(1 suppl):S98-S107.

7. World Health Organization [webpage on the Internet]. Guidelines for the screening care and treatment of persons with chronic hepatitis $\mathrm{C}$ infection - Updated version (April 2016). Available from: http://www. who.int/hepatitis/publications/hepatitis-c-guidelines-2016/en/. Accessed December 15, 2016.

8. Satsangi S, Mehta M, Duseja A, Taneja S, Dhiman RK, Chawla Y. Dual treatment with sofosbuvir plus ribavirin is as effective as triple therapy with pegylated interferon plus sofosbuvir plus ribavirin in predominant genotype 3 patients with chronic hepatitis C. J Gastroenterol Hepatol. 2017;32(4):859-863.

9. Kwo P, Gitlin N, Nahass R, et al. Simeprevir plus sofosbuvir (12 and 8 weeks) in hepatitis $\mathrm{C}$ virus genotype 1 -infected patients without cirrhosis: OPTIMIST-1, a phase 3, randomized study. Hepatology. 2016; 64(2):370-380.

10. Leroy V, Angus P, Bronowicki JP, et al. Daclatasvir, sofosbuvir, and ribavirin for hepatitis $\mathrm{C}$ virus genotype 3 and advanced liver disease: a randomized phase III study (ALLY-3+). Hepatology. 2016;63(5): $1430-1441$.

11. Feld JJ, Jacobson IM, Hézode C, et al; ASTRAL-1 Investigators. Sofosbuvir and velpatasvir for HCV genotype 1,2, 4, 5, and 6 infection. N Engl J Med. 2015;373(27):2599-2607.

12. Lawitz E, Matusow G, DeJesus E, et al. Simeprevir plus sofosbuvir in patients with chronic hepatitis $\mathrm{C}$ virus genotype 1 infection and cirrhosis: a phase 3 study (OPTIMIST-2). Hepatology. 2016;64(2):360-369.

13. Poordad F, Schiff ER, Vierling JM, et al. Daclatasvir with sofosbuvir and ribavirin for hepatitis $\mathrm{C}$ virus infection with advanced cirrhosis or post-liver transplantation recurrence. Hepatology. 2016;63(5): $1493-1505$.

14. Curry MP, O'Leary JG, Bzowej N, et al; ASTRAL-4. Sofosbuvir and velpatasvir for $\mathrm{HCV}$ in patients with decompensated cirrhosis. $N \mathrm{Engl}$ J Med. 2015;373(27):2618-2628.

15. Talavera Pons S, Boyer A, Lamblin G, et al. Managing drug-drug interactions with new direct-acting antiviral agents in chronic hepatitis $\mathrm{C}$. Br J Clin Pharmacol. 2017;83(2):269-293.

16. Micromedex ${ }^{\mathbb{B}}$ Solutions [homepage on the Internet]. Truven Health Analytics. Available from: http://www.micromedexsolutions.com/ home/dispatch. Accessed December 16, 2016. 
17. Buti M, Calleja JL, Lens S, et al. Simeprevir in combination with sofosbuvir in treatment-naïve and -experienced patients with hepatitis C virus genotype 4 infection: a Phase III, open-label, single-arm study (PLUTO). Aliment Pharmacol Ther. 2017;45(3):468-475.

18. Isakov V, Zhdanov K, Kersey K, et al. Efficacy of sofosbuvir plus ribavirin in treatment-naive patients with genotype-1 and -3 HCV infection: results from a Russian Phase IIIb study. Antivir Ther. 2016;21(8): 671-678

19. Foster GR, Pianko S, Brown A, et al. Efficacy of sofosbuvir plus ribavirin with or without peginterferon-alfa in patients with hepatitis $\mathrm{C}$ virus genotype 3 infection and treatment-experienced patients with cirrhosis and hepatitis C virus genotype 2 infection. Gastroenterology. 2016;149(6):1462-1470.

20. Foster GR, Afdhal N, Roberts SK, et al; ASTRAL-2 Investigators; ASTRAL-3 Investigators. Sofosbuvir and velpatasvir for HCV genotype 2 and 3 infection. N Engl J Med. 2015;373(27):2608-2617.

21. Mizokami M, Yokosuka O, Takehara T, et al. Ledipasvir and sofosbuvir fixed-dose combination with and without ribavirin for 12 weeks in treatment-naive and previously treated Japanese patients with genotype 1 hepatitis C: an open-label, randomised, phase 3 trial. Lancet Infect Dis. 2015;15(6):645-653.

22. Nelson DR, Cooper JN, Lalezari JP, et al; ALLY-3 Study Team. Alloral 12-week treatment with daclatasvir plus sofosbuvir in patients with hepatitis $\mathrm{C}$ virus genotype 3 infection: ALLY-3 phase III study. Hepatology. 2015;61(4):1127-1135.

23. Afdhal N, Reddy KR, Nelson DR, et al; ION-2 Investigators. Ledipasvir and sofosbuvir for previously treated HCV genotype 1 infection. $N$ Engl J Med. 2014;370(16):1483-1493.

24. Afdhal N, Zeuzem S, Kwo P, et al. Ledipasvir and sofosbuvir for untreated HCV genotype 1 infection. N Engl J Med. 2014;370(20):1889-1898.

25. Kowdley KV, Gordon SC, Reddy KR, et al; ION-3 Investigators. Ledipasvir and sofosbuvir for 8 or 12 weeks for chronic $\mathrm{HCV}$ without cirrhosis. N Engl J Med. 2014;370(20):1879-1888.

26. Omata M, Nishiguchi S, Ueno Y, et al. Sofosbuvir plus ribavirin in Japanese patients with chronic genotype $2 \mathrm{HCV}$ infection: an openlabel, phase 3 trial. J Viral Hepat. 2014;21(11):762-768.

27. Zeuzem S, Dusheiko GM, Salupere R, et al; VALENCE Investigators. Sofosbuvir and ribavirin in HCV genotypes 2 and 3. $N$ Engl J Med. 2014;370(21):1993-2001.

28. Jacobson IM, Gordon SC, Kowdley KV, et al; POSITRON Study; FUSION Study. Sofosbuvir for hepatitis C genotype 2 or 3 in patients without treatment options. N Engl J Med. 2013;368(20):1867-1877.

29. Lawitz E, Mangia A, Wyles D, et al. Sofosbuvir for previously untreated chronic hepatitis C infection. N Engl J Med. 2013;368(20): 1878-1887.

30. Gilead Sciences. Safety and efficacy of sofosbuvir plus ribavirin in treatment-naive adults with chronic genotype 1 or $3 \mathrm{HCV}$ infection. Available from: https:/clinicaltrials.gov/ct2/show/NCT02074514?ter $\mathrm{m}=\mathrm{NCT} 02074514 \& \mathrm{rank}=1$. NLM identifier: NCT02074514. Accessed December 1, 2016.
31. Gilead Sciences. Sofosbuvir plus ribavirin administered for either 12 or 24 weeks in treatment-naive and treatment-experienced Egyptian adults with chronic genotype 4 hepatitis $\mathrm{C}$ virus (HCV) infection. Available from: https:/clinicaltrials.gov/ct2/show/NCT01838590? term $=$ NCT01838590\&rank=1. NLM identifier: NCT01838590. Accessed December 1, 2016.

32. Gilead Sciences. Open-label study of sofosbuvir + ribavirin with or without peginterferon alfa-2a in subjects with chronic HCV infection who participated in prior Gilead HCV studies. Available from: https://clinicaltrials. gov/ct2/show/NCT01625338?term=NcT01625338\&rank=1. NLM identifier: NCT01625338. Accessed December 1, 2016.

33. He QF, Zhang QF, Zhang DZ. Efficacy and safety of ribavirin with sofosbuvir plus ledipasvir in patients with genotype 1 hepatitis $\mathrm{C}$ : a meta-analysis. Dig Dis Sci. 2016;61(11):3108-3117.

34. Gogela NA, Lin MV, Wisocky JL, Chung RT. Enhancing our understanding of current therapies for hepatitis $\mathrm{C}$ virus (HCV). Curr HIV/ AIDS Rep. 2015;12(1):68-78.

35. Pol S, Corouge M, Vallet-Pichard A. Daclatasvir-sofosbuvir combination therapy with or without ribavirin for hepatitis $\mathrm{C}$ virus infection: from the clinical trials to real life. Hepat Med. 2016;8:21-26.

36. Gara N, Ghany MG. What the infectious disease physician needs to know about pegylated interferon and ribavirin. Clin Infect Dis. 2013;56(11):1629-1636.

37. Sundaram V, Kowdley KV. Role of ledipasvir/sofosbuvir combination for genotype 1 hepatitis C virus infection. Hepat Med. 2016;8:75-80.

38. Lee R, Kottilil S, Wilson E. Sofosbuvir/velpatasvir: a pangenotypic drug to simplify HCV therapy. Hepatol Int. 2017;11(2):161-170.

39. Hézode C, Bronowicki JP. Ideal oral combinations to eradicate HCV: the role of ribavirin. J Hepatol. 2016;64(1):215-225.

40. Hwang Y, Kim W, Kwon SY, Yu HM, Kim JH, Choe WH. Incidence of and risk factors for thyroid dysfunction during peginterferon $\alpha$ and ribavirin treatment in patients with chronic hepatitis C. Korean J Intern Med. 2015;30(6):792-800.

41. Höner Zu Siederdissen C, Maasoumy B, Marra F, et al. Drug-drug interactions with novel all oral interferon-free antiviral agents in a large real-world cohort. Clin Infect Dis. 2016;62(5):561-567.

42. Vermehren J, Peiffer KH, Welsch C, et al. The efficacy and safety of direct acting antiviral treatment and clinical significance of drug-drug interactions in elderly patients with chronic hepatitis $\mathrm{C}$ virus infection. Aliment Pharmacol Ther. 2016;44(8):856-865.

43. Kao JH, Ahn SH, Chien RN, et al. Urgency to treat patients with chronic hepatitis C in Asia. J Gastroenterol Hepatol. Epub 2016 Dec 22.
Therapeutics and Clinical Risk Management

\section{Publish your work in this journal}

Therapeutics and Clinical Risk Management is an international, peerreviewed journal of clinical therapeutics and risk management, focusing on concise rapid reporting of clinical studies in all therapeutic areas, outcomes, safety, and programs for the effective, safe, and sustained use of medicines. This journal is indexed on PubMed Central, CAS,

\section{Dovepress}

EMBase, Scopus and the Elsevier Bibliographic databases. The manuscript management system is completely online and includes a very quick and fair peer-review system, which is all easy to use. Visit http://www.dovepress.com/testimonials.php to read real quotes from published authors. 